\title{
Folate regulation of axonal regeneration in the rodent central nervous system through DNA methylation
}

\author{
Bermans J. Iskandar, ${ }^{1}$ Elias Rizk, ${ }^{1}$ Brenton Meier, ${ }^{1}$ Nithya Hariharan, ${ }^{1}$ Teodoro Bottiglieri, ${ }^{2}$ \\ Richard H. Finnell, ${ }^{3}$ David F. Jarrard, ${ }^{4}$ Ruma V. Banerjee, ${ }^{5}$ J.H. Pate Skene, ${ }^{6}$ Aaron Nelson, ${ }^{1}$ \\ Nirav Patel, ${ }^{1}$ Carmen Gherasim, ${ }^{5}$ Kathleen Simon, ${ }^{1}$ Thomas D. Cook, ${ }^{7}$ and Kirk J. Hogan ${ }^{8}$ \\ 1Department of Neurological Surgery, University of Wisconsin, Madison, Wisconsin, USA. ${ }^{2}$ Baylor Research Institute, \\ Institute of Metabolic Disease, Dallas, Texas, USA. ${ }^{3}$ Texas Institute for Genomic Medicine, Houston, Texas, USA. \\ ${ }^{4}$ Department of Surgery, University of Wisconsin, Madison, Wisconsin, USA. ${ }^{5}$ Department of Biological Chemistry, \\ University of Michigan, Ann Arbor, Michigan, USA. ${ }^{6}$ Department of Neurobiology, Duke University Medical Center, Durham, North Carolina, USA. \\ ${ }^{7}$ Department of Biostatistics and ${ }^{8}$ Department of Anesthesiology, University of Wisconsin, Madison, Wisconsin, USA.
}

\begin{abstract}
The folate pathway plays a crucial role in the regeneration and repair of the adult CNS after injury. Here, we have shown in rodents that such repair occurs at least in part through DNA methylation. In animals with combined spinal cord and sciatic nerve injury, folate-mediated CNS axon regeneration was found to depend on injury-related induction of the high-affinity folate receptor 1 (Folr1). The activity of folate was dependent on its activation by the enzyme dihydrofolate reductase (Dhfr) and a functional methylation cycle. The effect of folate on the regeneration of afferent spinal neurons was biphasic and dose dependent and correlated closely over its dose range with global and gene-specific DNA methylation and with expression of both the folate receptor Folr1 and the de novo DNA methyltransferases. These data implicate an epigenetic mechanism in CNS repair. Folic acid and possibly other nontoxic dietary methyl donors may therefore be useful in clinical interventions to promote brain and spinal cord healing. If indeed the benefit of folate is mediated by epigenetic mechanisms that promote endogenous axonal regeneration, this provides possible avenues for new pharmacologic approaches to treating CNS injuries.
\end{abstract}

\section{Introduction}

The mature CNS is among tissues most refractory to healing after injury. In contrast to neuronal genesis in the fetal CNS, regeneration of axons in the adult brain and spinal cord is impaired by inhibitory molecules expressed in CNS myelin and glial cells in response to injury (1-3). In turn, damaged neurons in the adult CNS often fail to express genes required for effective axon regrowth and repair $(1,4)$. Recently, it has been observed that both the developing and injured adult mammalian CNS benefit from folic acid (FA) supplementation. First, periconceptional FA supplementation markedly reduces the incidence of neural tube and other malformations $(5,6)$. Furthermore, we have shown that parenteral FA produces up to a 10-fold, dose-dependent improvement in axon regrowth and functional recovery after injury to the adult CNS, an effect well in excess of other interventions (7). Corresponding efforts to improve neurological function through folate administration in neurodevelopmental diseases, including autism and depression, and other neuropsychiatric disorders are underway (8). However, the mechanisms underlying the efficacy of folate intervention remain unclear and may be related to diverse pathways in which single-carbon transfers participate.

Recognition that gene expression may be modified without altering genomic sequence via heritable covalent changes has contributed to an improved understanding of CNS pathophysiology in a

Conflict of interest: Teodoro Bottiglieri reports having been the chairman of the Advisory Board for Methylation Sciences Inc., holding stock options in Methylation Sciences Inc., and having received grant/research funding from Pamlab LLC, distributor of B vitamins as a medical food.

Citation for this article: J Clin Invest. 2010;120(5):1603-1616. doi:10.1172/JCI40000. number of inborn disorders (9-12). DNA methylation, an epigenetic mechanism ascribed mainly to the folate pathway and related metabolites, is a major gene-expression-modulating mechanism. Accordingly, we've reasoned that if genetic regulation of CNS development, regeneration, and repair is mediated by DNA methylation, it may also be responsive to FA and other factors that influence single-carbon transfers. We aimed, therefore, to determine whether interventions that modify single-carbon metabolism result in changes to genomic DNA methylation, which in turn correspond to the extent of axonal recovery and growth after experimental injury in the CNS. Herein, we report the consequences of specific interventions on enzymatic steps that comprise the folate pathway from cellular entry to methylation on axonal regeneration in the adult CNS after sharp injury. For this purpose, we use the spinal cord regeneration model (SCRM), which combines a bilateral dorsal column transection with a conditioning left sciatic nerve injury $(7,13)$. As depicted in a folate pathway schematic diagram (Figure 1), we show that agonists and antagonists of sequential reactions in folate metabolism exhibit dose-dependent inhibition and promotion of CNS repair, respectively, and that axonal regeneration relies upon the integrity of DNA methylation pathways. Additionally, we report for what we believe is the first time that axonal injury induces expression of the folate surface receptor folate receptor 1 (Folr1), thereby potentially enabling enhanced intracellular accumulation of folate; that suppression of the bioactivation of FA through dihydrofolate reductase (Dhfr) inhibits the regeneration of injured CNS axons; that global demethylation of spinal cord DNA accompanies injury, an effect prevented by folate supplementation; and that there is a direct, biphasic correlation between the proportion of regenerat- 


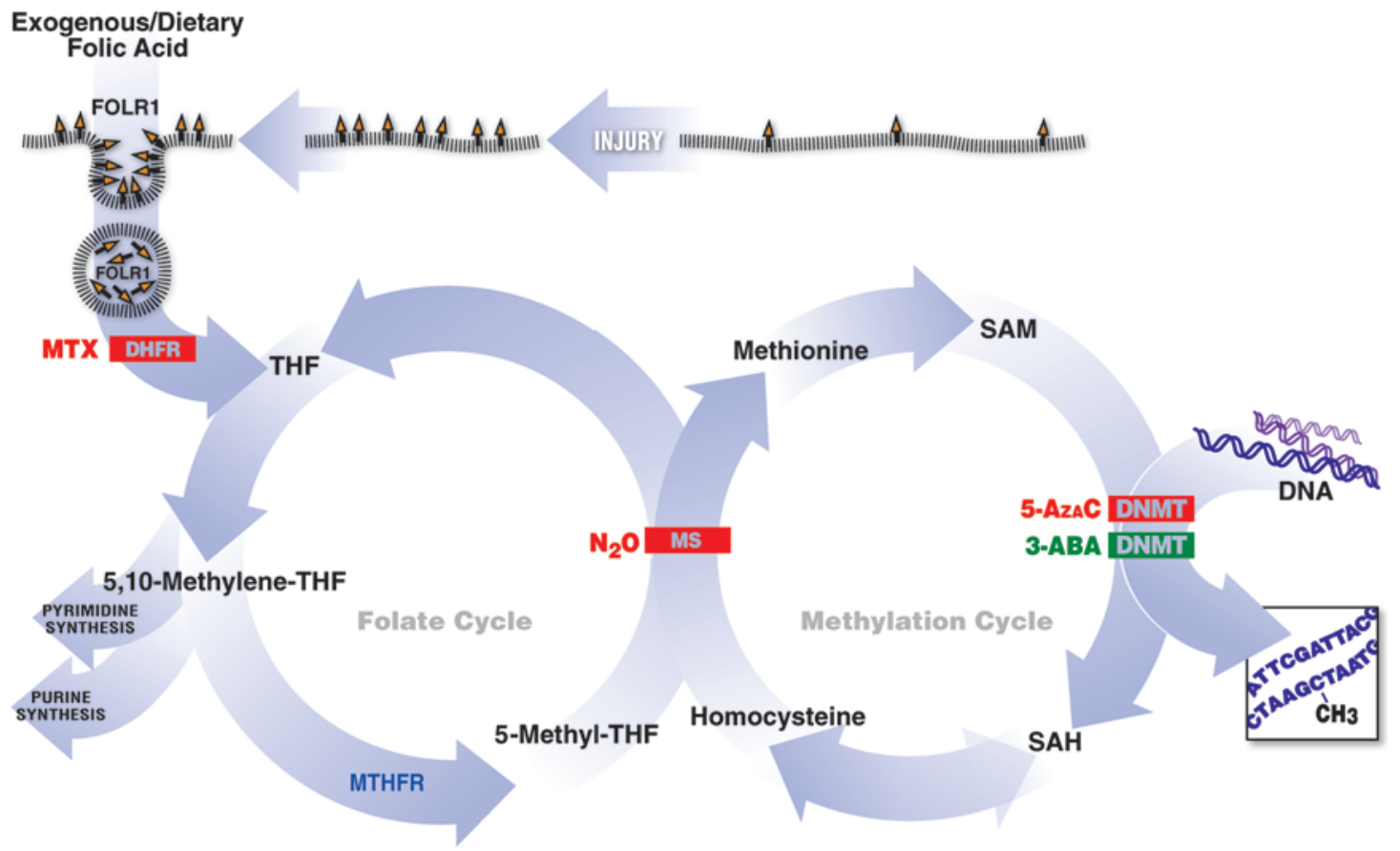

\section{Figure 1}

Summary of experimental interventions within the folate and methylation pathways. Folic acid enters the cell through Folr1, which is upregulated with injury. It is then converted to the active tetrahydrofolate (THF) form by Dhfr. This allows eventual production of nucleotides and certain amino acids as well as transfer of the methyl group into the methionine methylation cycle. The latter occurs through the B12-dependent MS step. Subsequently, SAM is the substrate used by the methyltransferase enzymes for the methylation reactions. Inhibition of Folr1, Dhfr, MS, and Dnmt suppresses CNS regeneration. In turn, activation of Dnmt enhances CNS regeneration.

ing afferent axons in the spinal cord, Folr1 expression, global DNA methylation, and the specific methylation of the Gadd45a gene associated with spinal injury and neurite outgrowth. Finally, we show that the dose-dependent association between regeneration after injury and the extent of spinal cord DNA methylation correlates with the expression of the de novo DNA methyltransferase enzymes Dnmt3a and Dnmt3b, but not with the expression of Dnmt 1 that is responsible for maintenance of DNA methylation.

\section{Results}

The SCRM model of spinal cord axonal regeneration combines a sharp bilateral cervical dorsal column transection with a unilateral "conditioning" sciatic nerve injury (spinal cord and sciatic nerve injury $[\mathrm{SCSN}])(7,13)$. Injuring the peripheral axon of the dorsal root ganglia (DRG) enhances growth of both the peripheral (sciatic) and central (dorsal column) components of the DRG (13). In addition, we have previously shown that the combination of peripheral nerve injury and i.p. FA supplementation is additive or synergistic, increasing the number of regenerating axons on the conditioned side nearly 10 -fold (7). Accordingly, the SCRM results reported in this study refer to the conditioned side of the spinal cord. For consistency, the combined bilateral dorsal columns and unilateral sciatic nerve injury model was used for all regeneration, molecular, and biochemical protocols.

Combined spinal cord and peripheral nerve injury induces expression of Folr 1 but not the reduced folate carrier. Folic acid does not diffuse into the cell. Therefore, specific active transport is essential. Two folate transport systems are available to the neuron: a transmembrane bidirectional anion channel, the reduced folate carrier (Rfc), with
2 isoforms, $\mathrm{Rfc} 1$ and $\mathrm{Rfc} 2$; and a receptor-mediated endocytotic pathway, the folate receptor (Folr) (previous nomenclature FR or folate-binding protein-FOLBP), with 4 known isoforms, $\alpha, \beta, \gamma$, and $\delta(14-16)$. Rfc1 is an anion exchanger ubiquitously expressed in diverse cells and tissues with low affinity for FA $(14,16)$. In contrast, the $\alpha$ isoform of Folr (Folr1) is a high-affinity, low-capacity system, operating at low concentrations of exogenous FA. To determine whether a sharp transection injury to the dorsal columns of the spinal cord and the sciatic nerve alters Folr1 and Rfc1 expression, mRNA transcript levels of the 2 genes were measured in the lumbar DRG cell bodies corresponding to the injured spinal and peripheral axons using in situ hybridization and in the injured spinal cord using RT-PCR. We observed a 2 -fold increase in the percentage of neurons expressing Folr 1 mRNA following injury to the adult spinal cord and sciatic nerve in rats (Figure 2, A, B, G, and $\mathrm{H}$ ). There was no change in $R f c 1$ mRNA expression either by RT-PCR or in situ hybridization (Figure 2, D and E). Next, we sought to correlate these results with immunohistochemical assays of Folr1 protein expression in the DRG neurons corresponding to the injured axons. A 6-fold increase in the percentage of neurons immunostaining for Folr 1 was observed in the injured animals compared with uninjured controls (Figure 2, C, I, and J), with minimal change seen in $\mathrm{Rf} 1$ protein levels in either group (Figure 2F). Confocal microscopy showed colocalization of the Folr1 expression with a neuronal marker indicating that the cells expressing the Folr are neurons rather than glia (Figure $2 \mathrm{~K}$ ).

Mice with reduced expression of Folr 1 do not regenerate spinal or optic axons in vivo or $D R G$ axons in vitro after injury. To determine whether increased Folr 1 expression after axonal injury is essential for the 
A

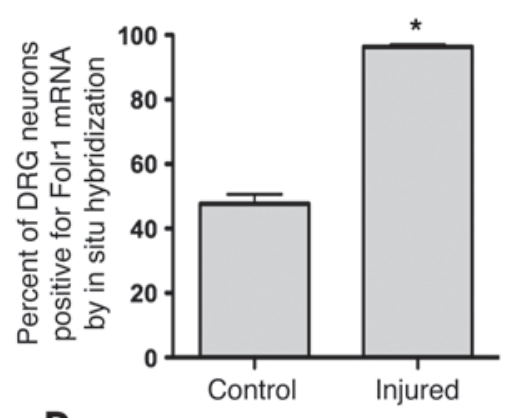

D

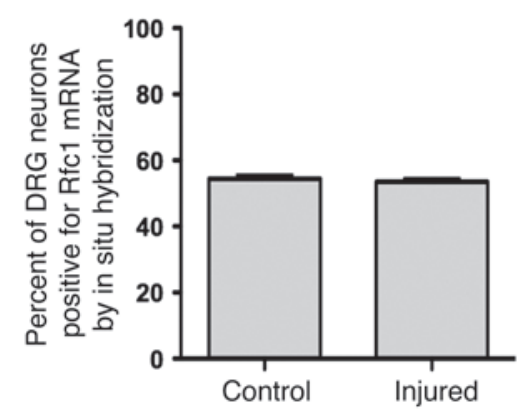

B

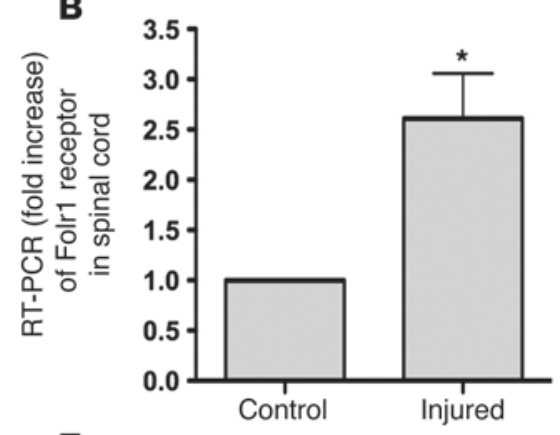

$\mathbf{E}$

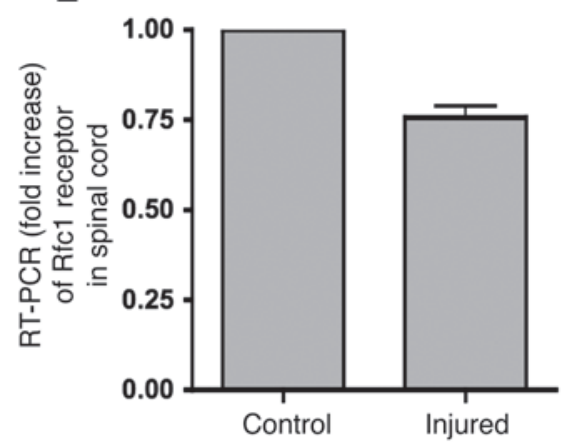

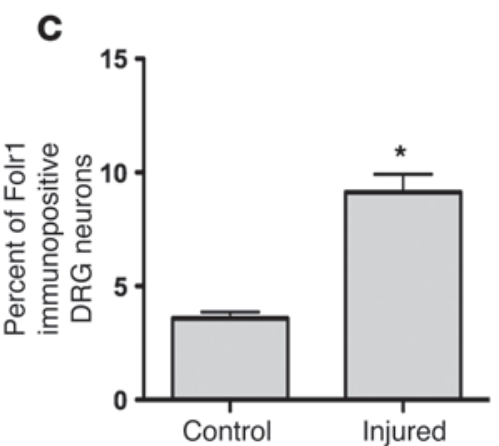

$\mathbf{F}$

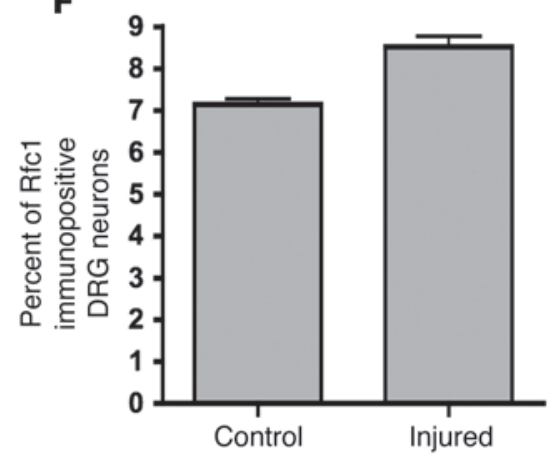

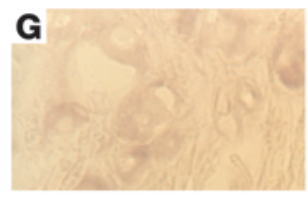
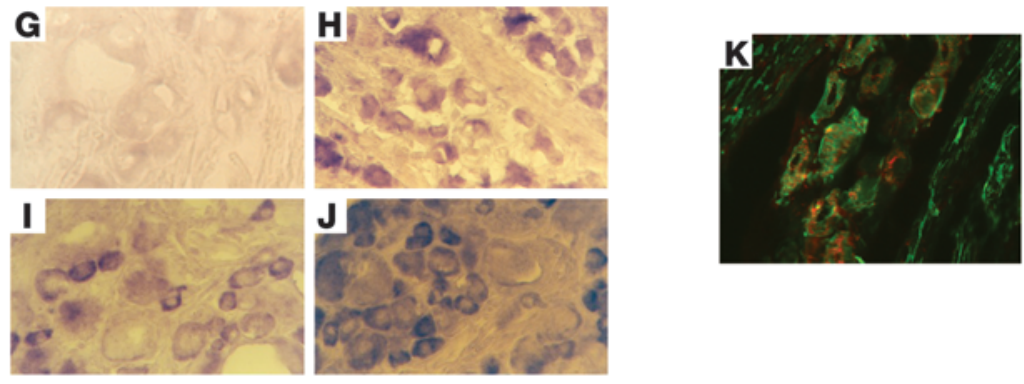

Figure 2

Combined spinal cord and peripheral nerve injury induces expression of Folr1 but not Rfc1. 4 days after sharp transection of both dorsal columns and the left sciatic nerve in rats, the left L5 and L6 DRGs were removed, sectioned, and mounted to undergo in situ hybridization (A, D) and immunohistochemistry (C, F) of the Folr1 and Rfc1 receptors. The spinal cord was removed for RT-PCR (B, E) and Western immunoblot (Figure 7, $A$ and $\mathbf{E})$. Note the significant upregulation of Folr1 with injury, with no change in the Rfc1 levels both in the spinal cord (SC) and DRG: in situ Folr1 $n=8$ (SC), 8 (DRG); in situ Rfc1 $n=5$ (SC), 5 (DRG); Folr1 RT-PCR $n=3$ (SC), 3 (DRG); Rfc1 RT-PCR $n=3$ (SC), 3 (DRG); immuno Folr1 $n=4$ (SC), 4 (DRG); immuno Rfc1 $n=4$ (SC), 4 (DRG). 2-tailed Student's $t$ test; mean \pm SEM; ${ }^{*} P<0.05$. (G, H) Folr1 in situ hybridization of DRG sections without $(\mathbf{G})$ and with $(\mathbf{H})$ preceding combined spinal cord and left sciatic nerve injury. (I, J) Folr1 immunostaining of DRG sections without (I) and with (J) preceding combined spinal cord and left sciatic nerve injury. (K) Confocal microscopy showing colocalization of the red Folr1 stain with the green neuronal (neurofilament) stain. Original magnification, $\times 40$.

proregenerative effect of FA, a sharp injury was administered to the cervical dorsal columns and left sciatic nerve of heterozygous Folr1 mice (17). After 48 hours, the left lumbar DRGs were removed to initiate in vitro neuronal cultures, as previously described (4). Whereas WT control mice demonstrated significant axonal elongation in the dissociated cells at 24 hours, Folr $1^{+/-}$animals exhibited little or no growth of long axons (>299 $\mu \mathrm{m}$ ) in culture (Figure 3). Absence of glia from the culture medium indicates that axonal regeneration is independent of the glial microenvironment. Sharp transection injuries were subsequently administered to the optic nerve and cervical dorsal columns of $\mathrm{Folr}^{+/-}$and WT mice, and a sciatic nerve graft was attached to the optic or spinal cord injury sites respectively, as previously reported $(7,13,18)$. After an interval of time adequate for growth of axons a distance of at least $1 \mathrm{~cm}$ into the graft (i.e., 2 weeks in the spinal model and 2 months in the optic model), the end of the graft was backfilled with a fluorescent tracer, and the corresponding cell bodies in the retina and DRG were counted. Supplementation of WT animals with i.p. FA at a dose previously shown to enhance regeneration $(80 \mu \mathrm{g} / \mathrm{kg})(7)$ produced at least a 2 -fold increase in the percentage of regenerating spinal neurons into the graft and almost a 10 -fold increase in the number of regenerating retinal ganglion cell (RGC) neurons compared with the WT animals without folate treatment. Conversely, no axonal regeneration was observed in the $\mathrm{Folr}^{+/-}$heterozygous animals receiving supplemental FA (Figure 4). Taken together, these results suggest that injury-induced augmentation of Folr1 receptor expression plays an essential role in the effects of FA on both spinal cord and optic axonal regeneration. 

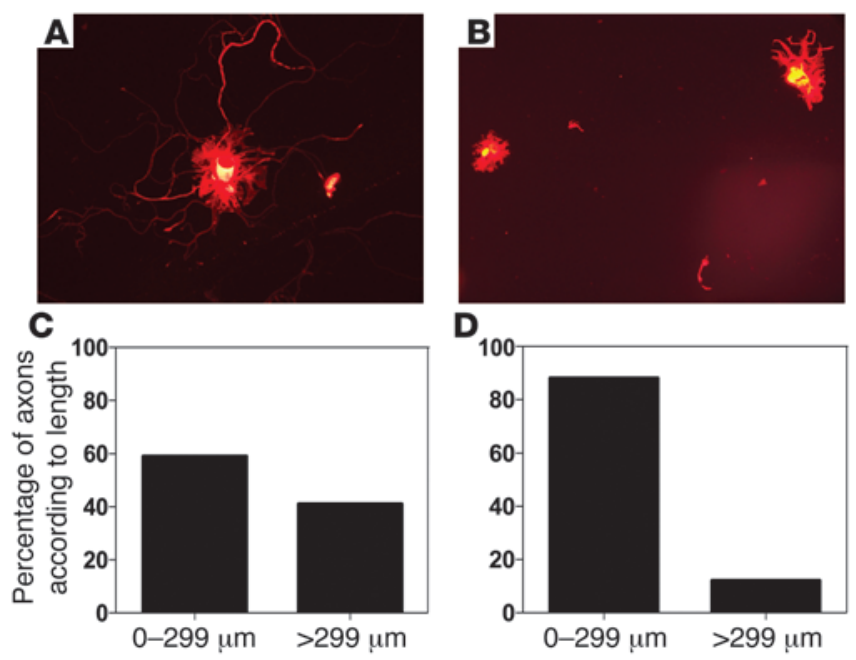

Dhfr bioactivation of FA is essential for folate-mediated CNS regeneration. Upon entry into the cell, FA is converted into active tetrahydrofolate form via 2 sequential reductions catalyzed by Dhfr (Figure 1). To determine whether the beneficial effects of FA on axonal regeneration depend upon its initial activation steps, the optic nerve and spinal cord experiments described above were conducted with and without FA in animals pretreated with the Dhfr antagonist methotrexate (MTX). A 10:1 inhibition of Dhfr activity was confirmed via Dhfr assay with only a mild change in protein levels observed on Western blot, indicating that MTX suppresses the enzymatic activity rather than the protein expression of Dhfr (Figure 5, A, C, and D). Compared with control animals, in which regrowth of injured axons into the grafts took place as described above, little or no spinal axonal regeneration in response to FA was observed in the MTX-treated animals (Figure 5B). In the absence of MTX, injury increased the protein and activity levels of Dhfr minimally, if at all (Figure 5, C and D). These results suggest that unencumbered intracellular conversion of FA to tetrahydrofolate in tandem with injury-mediated expression of Folr1 receptors are critical steps in folate-mediated axonal regeneration.

Combined spinal cord and peripheral nerve injury inhibits methyl cycling and S-adenosylmethionine bioavailability. Through its 5-methyltetrahydrofolate intermediary, the folate pathway donates methyl groups to the methylation cycle, enabling synthesis of S-adenosylmethionine (SAM), the primary methyl donor in neurons and all other cells of the CNS, upon its conversion to S-adenosylhomocysteine (SAH) (Figure 1) (19). SAH is hydrolyzed to replenish homocysteine stores. However, if homocysteine accumulates in excess, SAH formation is favored. In turn, SAH inhibits methyltransferase reactions, thereby exerting negative feedback on methylation reactions (20). Accordingly, measurement of the SAM/SAH ratio is an index of both pathway function and dysfunction (19). To determine whether a combined spinal cord and peripheral nerve injury results in altered single-carbon metabolism, the SAM/SAH ratio in the injured cervical segment of spinal cords 3 days after injury was measured. After injury, the SAM/SAH ratio declines by half, favoring SAH over SAM (Figure 6A), indicating that sharp injury suppresses single-carbon cycle function and the availability of methyl substituents by SAM.

Combined spinal cord and peripheral nerve injury suppresses methionine synthase activity, and methionine synthase inhibition abolishes folate-mediated axonal regeneration. By virtue of oxidation of the cobalamin

\section{Figure 3}

Mice with reduced expression of the Folr1 gene do not regenerate injured DRG axons in vitro. Forty-eight hours after an in vivo sharp injury to the spinal cord (dorsal columns) and left sciatic nerve in mice, the left lumbar DRGs that contain the cell bodies of the injured axons were removed, dissociated, and placed in a culture medium that sustains growth. In the WT animals (A, C), a significant number of axons reached a length of $300 \mu \mathrm{m}$; conversely, neurons from the Folr $1^{+-}$mice were less able to extend long axons. Instead, these neurons were more likely to show sprouting of short axons (B, D), indicating a decreased ability of the neurons to regenerate, as previously described $(4,24)$. Whereas $41 \%$ of neurons were able to extend axons greater than $299 \mu \mathrm{m}$ in the WT animals, only $12 \%$ of neurons showed such growth in the Folr $1^{+/-}$mice. Original magnification, $\times 20$.

cofactor of methionine synthase (MS), $\mathrm{N}_{2} \mathrm{O}$ irreversibly inhibits MS activity (21). To determine whether methylfolate-dependent synthesis of methionine from homocysteine by MS is a critical step in folate-mediated axonal regeneration, $\mathrm{N}_{2} \mathrm{O}$ was used to inactivate $\mathrm{MS}$ in vivo in animals with and without spinal cord injury and with and without FA supplementation. In animals breathing $\mathrm{N}_{2} \mathrm{O}$, axonal regeneration declined to baseline in the SCRM model, demonstrating that the single-carbon cycle is an essential component of the proregenerative effect of FA (Figure 6B). Direct measurement of MS activity (22) confirmed a decrement after $\mathrm{N}_{2} \mathrm{O}$ exposure (Figure 6C) and an increase in the spinal cord SAH level (Figure 6D), with no change in the MS protein levels observed on Western blots (not shown). In addition, a combined spinal cord and peripheral nerve injury suppressed MS activity, an effect synergistic with $\mathrm{N}_{2} \mathrm{O}$ (Figure 6C) and consistent with the rise in $\mathrm{SAH}$ described above. The decrement in MS activity was transient (Figure 6C), and its recovery after $\mathrm{N}_{2} \mathrm{O}$ treatment required 3 days to 2 weeks with or without spinal cord injury.

Combined spinal cord and peripheral injury suppresses and FA restores Dnmt 3 a and Dnmt3b, but not Dnmt1, protein levels in a biphasic fashion. DNA methyltransferases (Dnmts) participate in direct methylation of $\mathrm{CPG}$ dinucleotides in the mammalian genome, using methyl group provided by SAM. Dnmt1 maintains the pattern of DNA methylation (i.e., methylation of hemimethylated sites), while Dnmt3a and Dnmt3b participate in de novo methylation (i.e., methylation of previously unmethylated sites). To determine the relative contributions of the Dnmts to CNS injury and repair, Dnmt1, Dnmt3a, and Dnmt3b protein levels were measured prior to and following combined spinal cord and peripheral nerve injury using Western blot analysis. No detectable effect on Dnmt1 protein levels after injury was observed (Figure 7, A and D). However, injury suppressed Dnmt3a and Dnmt3b protein levels in the spinal cord, and i.p. FA treatment restored both Dnmt3a and Dnmt3b levels to preinjury baselines. The magnitude of de novo Dnmt protein expression in response to increasing doses of parenteral folate was biphasic (Figure 7, A-C). Interestingly, this correlates closely with our earlier observations (7), confirmed here in a different group of animals (Figure 7F), in which we show that the proregenerative effect of FA is dose dependent, with peak effects observed at $80 \mu \mathrm{g} / \mathrm{kg}$. No toxicity is observed at higher doses, but beneficial effects gradually diminish to baseline in a dose-dependent fashion. Moreover, the protein levels of the methyltransferases were measured in response to antagonists of Dhfr and MS. Dnmt 1 levels again show minimal change with any intervention, while Dnmt3a and Dnmt3b protein levels decrease with MTX and are eliminated with nitrous oxide (Figure 7, A-C). 

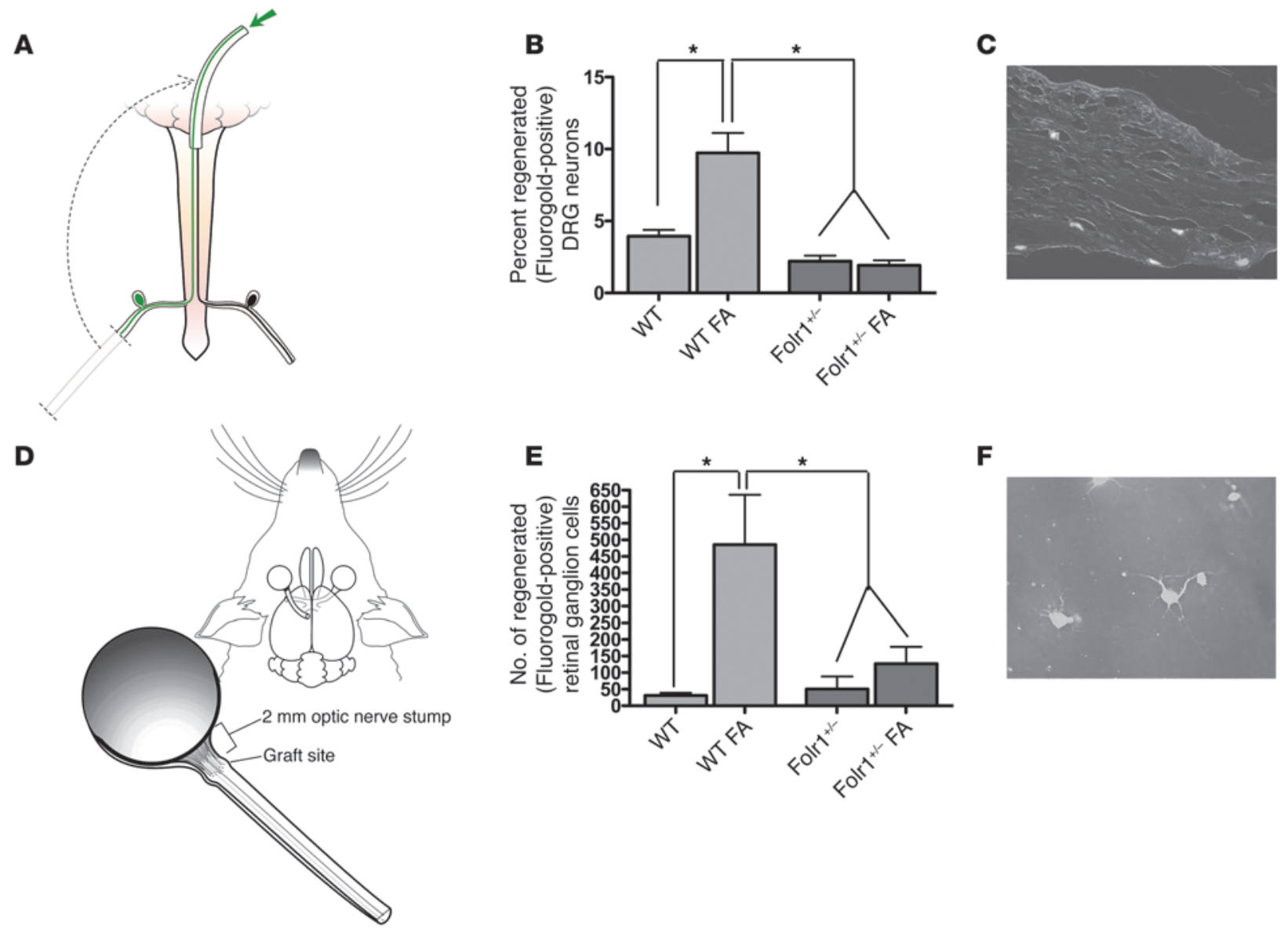

Figure 4

Mice with reduced expression of the Folr1 gene do not regenerate injured spinal and optic axons in vivo. (A) Mouse SCRM in which a sciatic nerve graft is implanted at the site of bilateral C3 dorsal column lesion. Removal of the left sciatic nerve of the animal effectively created a "conditioning" peripheral nerve injury on that side, which has been shown to enhance growth of injured spinal axons into the graft. At 2 weeks, a fluorescent tracer was placed at the free end of the graft and was detected in the conditioned (left) lumbar DRG neuron cell bodies of the axons that had grown into the graft. (B) Regeneration of spinal sensory axons into a peripheral nerve graft in WT and Folr $1^{+/-}$mice with and without FA supplementation. $n=10$ (WT); 10 (WT FA); 10 (Folr $\left.1^{+/}\right)$; 10 (Folr $1^{+/-}$). One-way ANOVA with Bonferroni's correction. (C) Fluorescent (i.e., regenerated) neurons in a DRG section. Original magnification, $\times 10$. (D) Mouse retinal regeneration model in which a sciatic nerve graft was implanted to the proximal stump of an axotomized optic nerve. At 2 months, a fluorescent tracer was placed at the free end of the graft and was detected in the RGC cell bodies of the axons that had grown into the graft. (E) Regeneration of RGC axons into a peripheral nerve graft in WT and Folr1+/- mice with and without FA supplementation. (F) Fluorescent RGC neurons on a retinal flat mount. Original magnification, $\times 40$. $n=10$ (WT); 10 (WT FA); 10 (Folr $\left.1^{+-}\right)$; 8 (Folr $\left.1^{+/}\right)$. One-way ANOVA with Bonferroni's correction; mean \pm SEM; ${ }^{*} P<0.05$.

Although Folr1 expression increases after neural injury, the response of Folr1 expression to increasing doses of FA is biphasic, peaking at $80 \mu \mathrm{g} / \mathrm{kg}$ as well (Figure $7, \mathrm{~A}$ and $\mathrm{E}$ ).

Combined spinal cord and peripheral nerve injury suppresses spinal cord DNA methylation, and FA restores methylation levels in a biphasic fashion. To determine whether injury- and folate-dependent alterations in Dnmt levels correlate with global DNA methylation in the spinal cord, methyl group incorporation was measured by radioactive assay (23) in spinal cords 3 days after sharp bilateral cervical dorsal column combined with left sciatic nerve injury to replicate the injury used in the SCRM regeneration model. Injury decreases global genomic methylation by $40 \%$, an effect that is prevented by FA supplementation (Figure 8). Moreover, a dose-dependent biphasic increase and subsequent decrease in spinal cord global methylation was also observed (Figure 9), closely tracking the biphasic curves of FA dose-dependent affer- ent spinal axon regeneration (Figure $7 \mathrm{~F}$ and previous results in ref. 7) as well as de novo methyltransferase expression. It is important to note that lower counts in Figures 8 and 9 indicate higher methylation values. Although global methylation is measured 3 days after the injury whereas regeneration is tested at 2 weeks, there is no difference in methylation levels between these 2 time points (data not shown). "Regenerative competence" is thought to be initiated 24-48 hours after injury and persist until target reinnervation (24).

Thus, FA inhibits a hypomethylation response created by injury in a dose-dependent fashion, and DNA methylation together with Dnmt3a and Dnmt3b protein levels correlate with the capacity of the spinal neurons to regenerate their injured axons to a ceiling at the dose that produces a peak methylation response $(80 \mu \mathrm{g} / \mathrm{kg})$. Thereafter, increments in FA reverse axonal regeneration to baseline for reasons that remain unclear. 
A

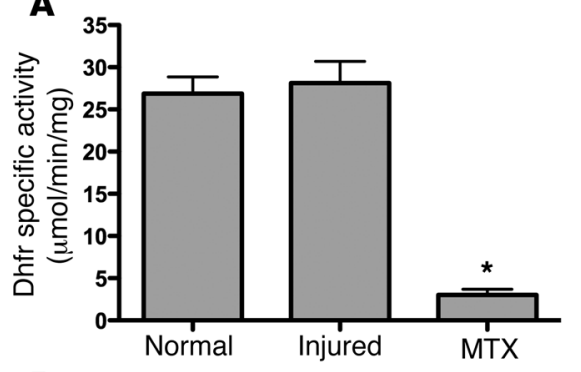

B

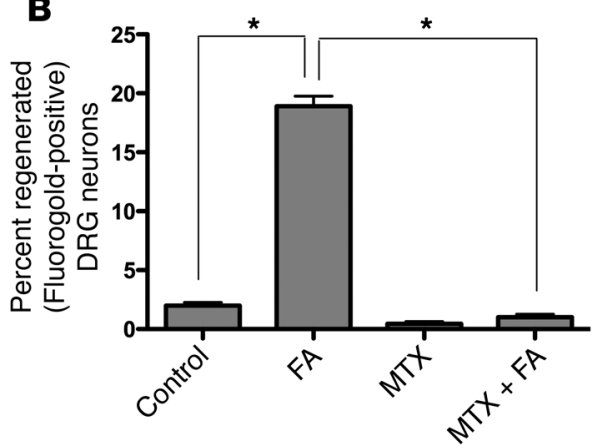

D

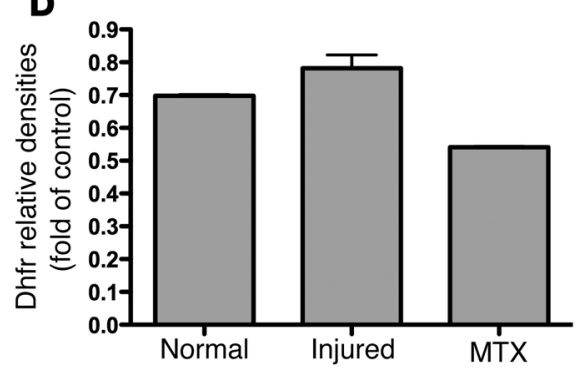

\section{Discussion}

Parenteral FA administration prior to and following injury improves the regeneration in vivo of injured sensory spinal and optic axons into transplanted peripheral nerve grafts (8). Herein, we report the effects of interventions in folate pathways from absorption and activation to utilization that are targeted to resolve the cellular mechanisms responsible for the proregenerative effects of folate. We demonstrate for what we believe is the first time that a combined spinal cord and peripheral nerve injury induces spinal cord expression of the high-affinity Folr1 receptor (but not the low-affinity $\mathrm{Rf} 1$ receptor) and triggers global DNA hypomethylation of the postinjury spinal cord genome. Accordingly, we propose that increased Folr1 expression enables increased FA to enter the cell and that FA in turn regulates receptor activation in a dose-dependent fashion. In addition, we demonstrate that reduction of FA to its active form by Dhfr is essential to its proregenerative effects. In turn, the dose dependency of global DNA methylation in the CNS via de novo methylation enzymes Dnmt3a and Dnmt3b, but not maintenance enzyme Dnmt1, parallels the dose dependency of folate-mediated recovery.

Dnmt agonist promotes, and Dnmt antagonist inbibits, growth of injured sensory spinal axons into a peripheral nerve graft. To determine whether the Dnmt3a and Dnmt3b methyltransferases are critical to postinjury folate-mediated recovery, the regeneration of afferent spinal axons into a graft was assessed as above in rats pretreated with the Dnmt agonist 3-aminobenzamide (3-ABA) $(15 \mathrm{mg} / \mathrm{kg}$ i.p.) (25) and antagonist 5-azacytidine (5-AzaC) $(0.1 \mathrm{mg} / \mathrm{kg}$ i.p.) (26) with and without FA. 5-AzaC partially blocked folate-mediated regeneration (Figure 10A). 3-ABA, which enhances the activity of the methyltransferases through inhibition of poly(ADP-ribose) polymerases (25), promoted regeneration when administered alone, but it did not add to folate-mediated recovery in the single dose studied (Figure 10B).

Combined spinal cord and peripheral nerve injury increases methylation of the Gadd45a promoter, and FA increases methylation in a biphasic fashion in 12 of 18 CPG sites. To determine whether the effect of FA on global methylation is associated with methylation of specific genes associated with axonal regeneration, we examined the methylation status of $18 \mathrm{CpG}$ sites on the Gadd45a promoter. The percentage of methylation of 12 of these sites increased with spinal cord injury and increased further in a biphasic fashion with FA supplementation. As with global methylation, the dose-dependent configuration of these changes was similar in peak folate doses and overall morphology to those observed with folate-mediated spinal cord regeneration (Figure 11).
Inhibition of enzymatic steps along the folate pathway impairs axonal regeneration. For reasons yet to be elucidated, the beneficial effects of folate supplementation after CNS injury also exhibit a biphasic dose response curve with optimal regeneration occurring at a dose of $80 \mu \mathrm{g} / \mathrm{kg}$. A strikingly parallel biphasic response is also observed in both the methylation status of the CNS genome and the protein levels of the Folr as well as in the de novo methyltransferases in response to folate after injury. Specifically, $80 \mu \mathrm{g} / \mathrm{kg}$ of parenteral FA optimizes Folr1 expression, Dnmt3a and Dnmt3b protein levels, the methylation status of the adult CNS, and its ability to regenerate after injury. Biphasic methylation changes are global across the genome and in the promoter of at least 1 gene, Gadd45a. Gadd45 is a cell-cycle gene linked to both neuronal activity $(27,28)$ and DNA methylation (29). Gadd45a controls neurite outgrowth (28) and is induced by spinal cord injury to control neuronal damage and cell death (27).

Doses of FA higher than $80 \mu \mathrm{g} / \mathrm{kg}$ induce relative hypomethylation associated with reduced de novo methyltransferase levels and decreased axonal regeneration. The effect, which reaches levels comparable to those seen in untreated groups only at very high doses, suggests a loss of benefit from higher folate doses rather than toxicity. Others have reported biphasic effects related to the folate and methylation pathways in tissues of distinct germline derivation, e.g., monocytes and vascular smooth muscle, suggesting that the effect is not confined to neuronal cells (30-32). While the prore- 

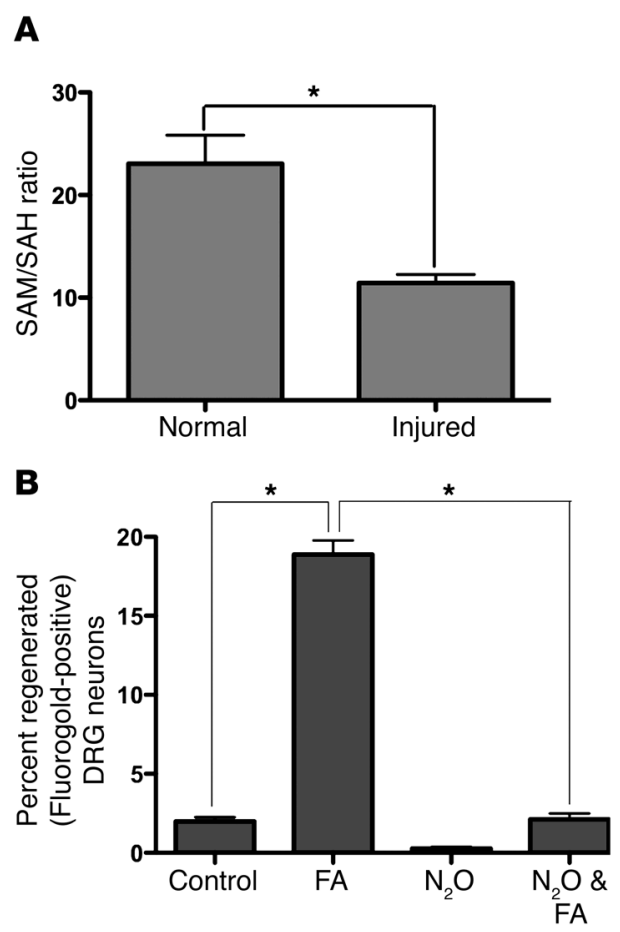

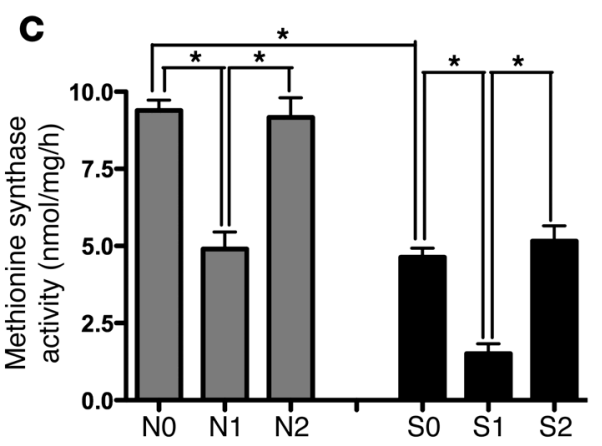

D

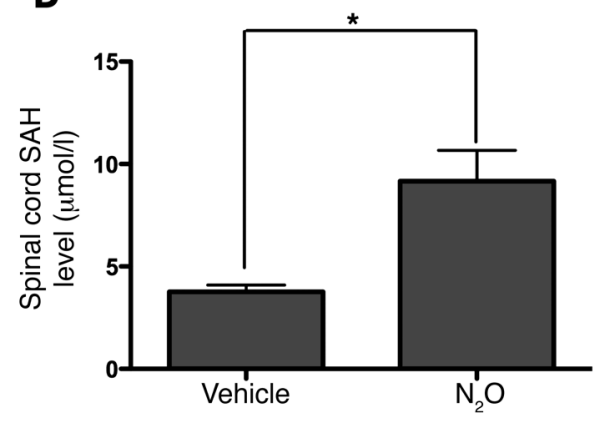

\section{Figure 6}

Combined spinal cord and peripheral nerve injury inhibits methyl cycling, SAM bioavailability, and MS activity; and MS inhibition abolishes folate-mediated axonal regeneration. Injury to the rat spinal cord and left sciatic nerve causes a diminution in the SAM/SAH ratio $(n=6$ [normal]; $n=6$ [injured]. Student's $t$ test; mean \pm SEM; $\left.{ }^{*} P<0.05\right)(A)$, suggesting a direct effect of injury on DNA methylation. To confirm this observation, spinal axonal regeneration was measured in the SCRM model on the "conditioned" side after treatment with $\mathrm{N}_{2} \mathrm{O}$. $\mathrm{N}_{2} \mathrm{O}$ is a specific inhibitor of the MS enzyme; thus it interferes with the entry of active folate into the methionine methylation cycle. $\mathrm{N}_{2} \mathrm{O}$ suppressed axon growth to below control levels. $n=10$ (untreated); $n=7(\mathrm{FA}) ; n=8\left(\mathrm{~N}_{2} \mathrm{O}\right) ; n=8(\mathrm{FA})$. One-way ANOVA with Bonferroni's correction; mean $\pm \mathrm{SEM}$; ${ }^{*} P<0.05$ (B). To determine whether $\mathrm{N}_{2} \mathrm{O}$ suppresses $\mathrm{MS}$, MS activity and $\mathrm{SAH}$ levels were measured in the spinal cord after $\mathrm{N}_{2} \mathrm{O}$ exposure. $\mathrm{N}_{2} \mathrm{O}$ suppressed MS activity (C) with no change in the enzyme protein levels by Western analysis (not shown) and caused a corresponding rise in SAH (D). Note the drop in MS activity after injury and after $\mathrm{N}_{2} \mathrm{O}$ treatment. Recovery from the $\mathrm{N}_{2} \mathrm{O}$ effect occurs by 3 days (C). N, no injury; S, spinal cord injury; $\mathrm{NO}$ and $\mathrm{S} 0, \mathrm{No} \mathrm{N}_{2} \mathrm{O}$ treatment; $\mathrm{N} 1, \mathrm{~N}_{2} \mathrm{O}$ given the day before removing the spinal tissue; $\mathrm{N} 2, \mathrm{~N}_{2} \mathrm{O}$ given 3 days before removing the spinal tissue; $\mathrm{S} 1, \mathrm{~N}_{2} \mathrm{O}$ treatment every other day for 2 weeks; $\mathrm{S} 2, \mathrm{~N}_{2} \mathrm{O}$ given 2 weeks before removing spinal tissue. $n=3$ in each group; each specimen was run in triplicate. One-way ANOVA with Bonferroni's correction; mean $\pm \mathrm{SEM},{ }^{*} P<0.05$.

generative effect of FA is greater than that of other interventions reported to date, the declining effect with doses higher than 80 $\mu \mathrm{g} / \mathrm{kg}$ indicates a ceiling on the regenerative potential provided by FA supplementation. Such a limitation may be related to transcriptional regulation of the de novo methyltransferases and/or the Folr. Furthermore, a recent report shows that FA inhibits the uptake of 5-methyltetrahydrofolate by the Folr in a dose-dependent fashion and suggests that FR- $\alpha$ (Folr 1 ) is the major uptake mechanism at low concentrations, whereas the Rfc is the major uptake mechanism at higher concentrations (33). Experiments are underway to identify specific factors that affect the transcriptional regulation of the methyltransferases and Folr1 receptor and to determine how these are in turn affected by folate supplementation.

The ability to impart epigenetic methylcytosine signals to DNA depends on substrate availability (e.g., FA), Folr function, the enzymes of methionine metabolism, and the ability to transfer methyl groups to DNA strands via specific methyltransferases. We propose that FA-induced axonal regeneration operates through enhanced DNA methylation, which in turn may result in biphasic consequences in the expression of proteins underlying axonal growth and regeneration. Evidence in favor of this hypothesis includes the following: (a) inhibition of sequential steps within the folate and methylation pathways strongly inhibits the proregenerative effect of FA after spinal and optic injury; (b) enhancing methyltransferase function increases the regeneration of injured spinal neurons; and (c) the effective dose of FA has a narrow biphasic range with an optimal dose response at $80 \mu \mathrm{g} / \mathrm{kg}$ in maximizing spinal regeneration, restoring normal levels of global methylation in the injured spinal cord, and amplifying the expression of the de novo methyltransferases. This is consistent with earlier reports showing a relationship between DNA methylation and the CNS. Aberrant methylation is associated with reduced neurogenesis, neural stem cell differentiation, and increased genomic instability (34); DNA methylation is altered in brain ischemia (35) and in at least 3 clinical disorders associated with mental impairment, including Rett syndrome, ICF syndrome (immunodeficiency, centromeric heterochromatin, facial anomalies), and fragile $\mathrm{X}$ syndromes (36); and de novo Dnmt activity is necessary for memory consolidation in the hippocampus (37). However, the present hypothesis does not exclude alternative mechanisms. For example, hypomethylation may be a bystander to toxic consequences of homocysteine accumulation. Increasing doses of homocysteine in vascular smooth muscles has been shown to increase the expression of Dnmt3a and Dnmt3b as 
A
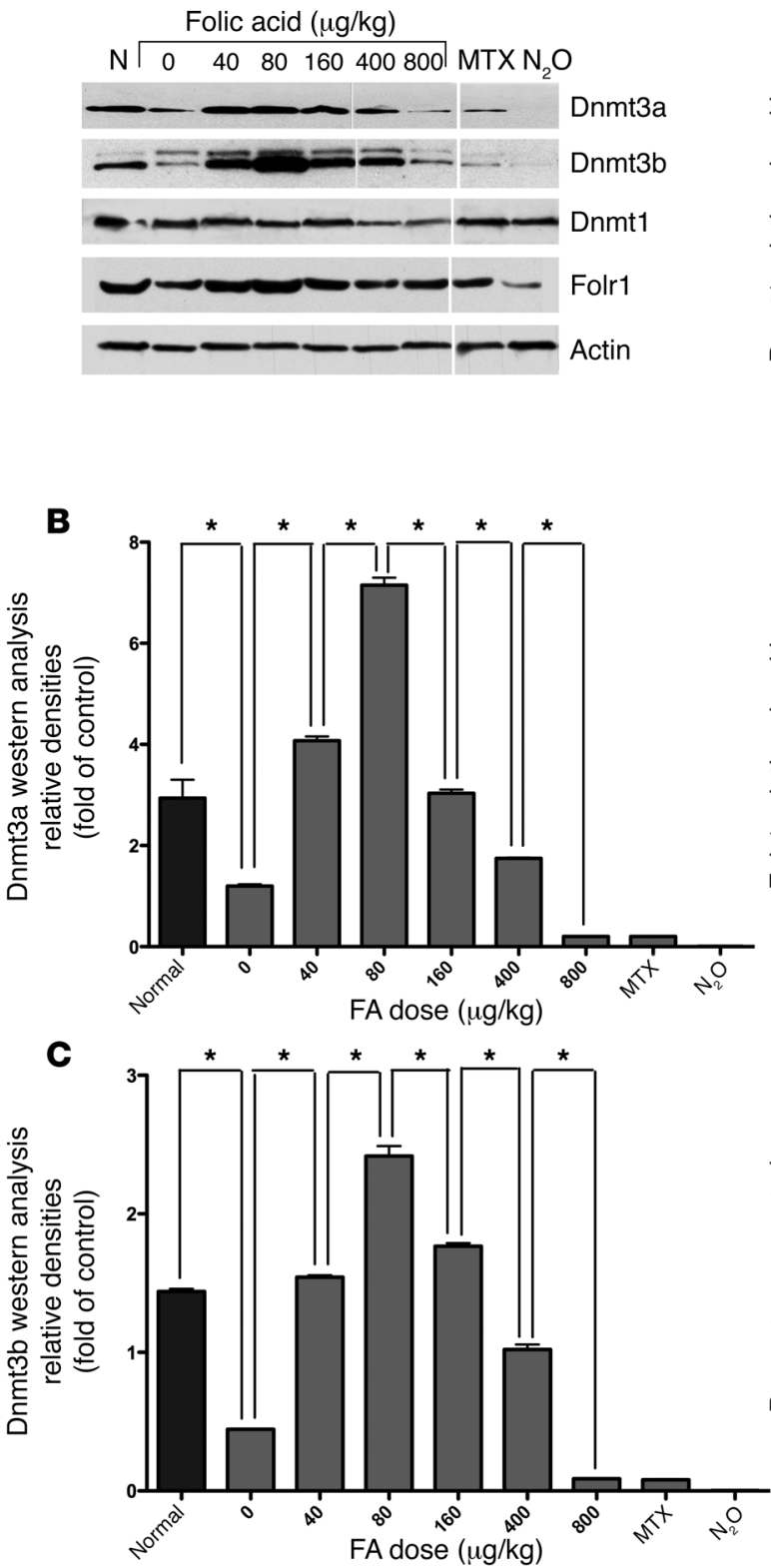

D
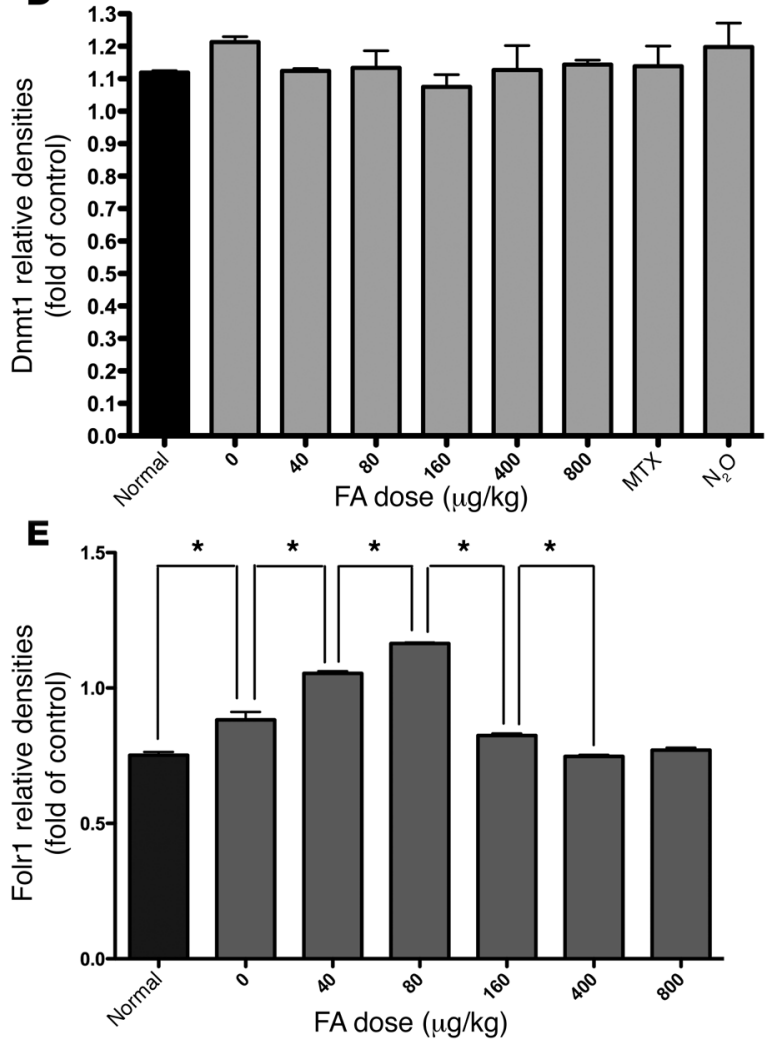

$\mathbf{F}$

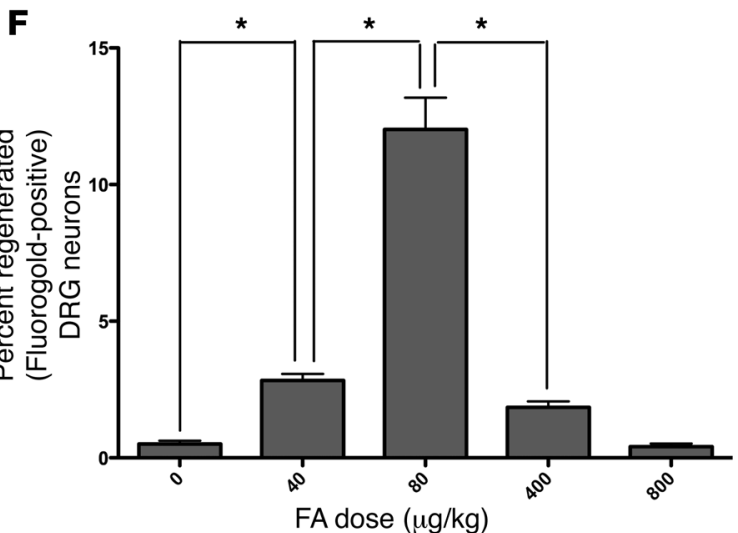

Figure 7

Combined spinal cord and peripheral nerve injury suppresses the protein levels of the de novo methyltransferases Dnmt3a and Dnmt3b, but not the maintenance methyltransferase Dnmt1, and FA treatment restores the levels in a biphasic fashion that parallels the biphasic response to FA treatment seen with spinal regeneration and Folr1 expression. (A-D) Combined spinal cord and peripheral nerve injury suppresses Dnmt3a and Dnmt3b protein levels in mouse spinal cords, with no effect on Dnmt1. Furthermore, FA treatment restores these levels in both Dnmt3a and Dnmt3b. When increasing doses of FA are given i.p., a biphasic response is observed in the de novo methyltransferases Dnmt3a and Dnmt3b, with maximal protein levels occurring at $80 \mu \mathrm{g} / \mathrm{kg}$. (F) Folic acid supplementation was previously shown to affect rat CNS regeneration following injury in a dose-dependent manner that corresponds tightly to the de novo Dnmt response. These results, obtained from our laboratory and previously reported by Iskandar et al. (7), are confirmed here in a different group of animals. One-way ANOVA with Bonferroni's correction; $n$ (FA dose) = $9(0 \mu \mathrm{g} / \mathrm{kg}) ; 9(40 \mu \mathrm{g} / \mathrm{kg}) ; 5(80 \mu \mathrm{g} / \mathrm{kg}) ; 9(400 \mu \mathrm{g} / \mathrm{kg}) ; 9(800 \mu \mathrm{g} / \mathrm{kg})$. Mean $\pm \mathrm{SEM} ; P<0.05$ for all comparisons except 0 versus 400,0 versus 800 , and 40 versus 400 . Conversely, treatment with MTX significantly decreases Dnmt3a and Dnmt3b protein levels, while treatment with $\mathrm{N}_{2} \mathrm{O}$ nearly eliminates Dnmt3a and Dnmt3b protein expression. Neither injury nor folate, MTX, nor $\mathrm{N}_{2} \mathrm{O}$ affect the levels of the maintenance methyltransferase Dnmt1 (A, E). Furthermore, although Folr1 expression increases after injury, its response to increasing doses of FA is similarly biphasic. (A) Western blots. All lanes were run on the same gel. Noncontiguous lanes are separated by a thin white line in the figure. (B-D, E) Plots of the band densities relative to the corresponding actin bands. One-way ANOVA with Bonferroni's correction; $n=3$ in each group; mean \pm SEM; ${ }^{\star} P<0.05$. 


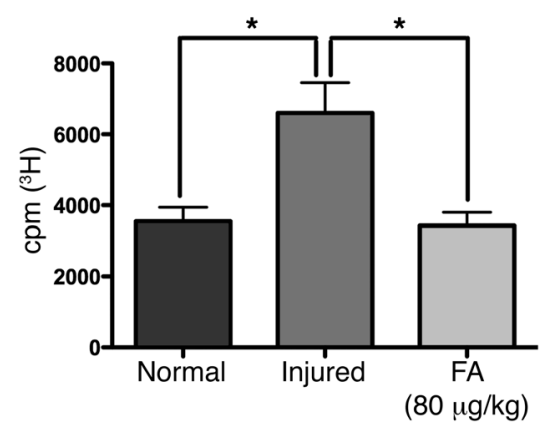

Figure 8

Combined spinal cord and peripheral nerve injury suppress spinal cord DNA methylation, and FA restores methylation levels to baseline. A global methylation assay (23) was performed to measure methyl group incorporation into DNA from rat spinal cord tissue in response to dorsal column/left sciatic nerve injury and FA supplementation. Global methylation in the spinal cord tissue was measured by a scintillation counter indicating the amount of radioactively labeled methyl groups incorporated into the sequence. The cpm values of each experimental group correspond inversely to the extent of global DNA methylation in the spinal cord in vivo. We show that global methylation is suppressed by injury, and the methylation levels are restored in response to the $80 \mu \mathrm{g} / \mathrm{kg}$ dose of FA. N, uninjured control spinal cord; I, spinal cord/sciatic nerve injury; $\mathrm{F}$, spinal cord/sciatic nerve injury and treatment with FA at $80 \mu \mathrm{g} / \mathrm{kg} . n=20(\mathrm{~N}) ; n=32(\mathrm{I}) ; n=33(\mathrm{~F})$. One-way ANOVA with Bonferroni's correction; mean $\pm \mathrm{SEM}$; ${ }^{*} P<0.05$.

well as global DNA methylation in a biphasic fashion (20). Higher order effects of methylation on protein function and histone conformation have also been described.

In summary, we show that folate-mediated CNS regeneration depends on injury-related induction of Folr 1 expression, intact intracellular folate activation, and a functional methylation cycle. In turn, we demonstrate that the biphasic and dose-dependent effects of folate on the regeneration of afferent spinal neurons correlate closely over a dose range with global and gene-specific DNA methylation and with expression of the de novo Dnmts. We suggest that these observations implicate a role for epigenetic mechanisms of CNS repair. If confirmed, our data may help to explain the refractory nature of the CNS to conventional healing interventions and point to novel approaches to promote repair of the injured brain, spinal cord, and other tissue through modification of the methylation milieu.

\section{Methods}

\section{Surgery}

All surgery experiments were conducted with approval from the University of Wisconsin Research Animal Resources and Care Committee and in accordance with published NIH guidelines. We employed a spinal cord injury model to analyze alterations in Folr expression, global methylation, and methyltransferase levels. This model was also used as the conditioning injury for cell culture experiments. Two models to assess optic (optic nerve regeneration model [ONRM]) and spinal (SCRM) axonal elongation after injury in vivo were employed for the experiments using WT and $\mathrm{Folr}^{+/-}$mice, MTX treatment in rats, and nitrous oxide treatment in rats. As demonstrated previously $(7,13)$, optimal conditions for spinal axonal regeneration in this model (SCRM below) require a conditioning sciatic nerve injury in addition to the dorsal column transections. In order to maintain a consistent injury throughout all protocols, we subjected all animals used in molecular and biochemical experiments to the same spinal cord and peripheral nerve combination injury (SCSN below) employed in the regeneration experiments.

SCSN injury. A 10:1 mixture of ketamine/xylazine was administered i.m. under sterile conditions prior to surgery. The cervical cord was exposed by a C3 laminectomy and the dura opened under aseptic conditions. A 1 -mm-deep dorsal column injury was made in both posterior columns using sharp jeweler forceps, severing the primary somatosensory axons ascending the spinal cord. A complete transection of the left sciatic nerve was performed through a separate incision to replicate the injury in the regeneration (SCRM) model. Four days postoperatively, the rats were anesthetized and perfused intracardially with $4 \%$ PFA. The L5 DRGs were removed bilaterally and fixed using 4\% PFA for 10 hours followed by $30 \%$ sucrose for 8 hours. DRGs were then frozen in TBS Tissue-Tek OCT compound (Sakura-Finetek) and sections prepared on a $-20^{\circ} \mathrm{C}$ cryostat. Sections were cut at a thickness of $12 \mu \mathrm{m}$, placed onto glass slides, and stored at $-80^{\circ} \mathrm{C}$ for later in situ hybridization and immunohistochemistry (below). For RT-PCR, the unperfused spinal cord was removed 4 days after the injury and processed as detailed below.

SCRM. Adult male Sprague-Dawley rats or male Folr $1^{+/+}$or Folr $1^{+/-}$mice were subjected to surgery under ketamine/xylazine anesthesia, as previously described (Figure 4) $(4,38,39)$. The cervical cord was exposed through a C3 laminectomy and dural opening. Using a pair of sharp jeweler forceps, a well-defined 0.5 -mm-deep injury was made in both posterior columns. A $2-\mathrm{cm}$ sciatic nerve segment harvested from the left hind limb was then implanted at the injury site using 10-0 nylon sutures in the pia. The other end of the graft was allowed to lie freely under the skin. Two weeks later, the incision was reopened under a similar anesthetic and a gelfoam soaked in $5 \mu \mathrm{l}$ of the retrograde tracer Fluoro-Gold was placed at the free end of the nerve graft. The fluorescent tracer is picked up solely by axons that have grown into the graft and undergoes retrograde transport (13). 24 hours later, the animal was deeply anesthetized and perfused through the heart with $4 \%$ paraformaldehyde. The L5 DRGs were removed bilaterally, postfixed, incubated in $30 \%$ sucrose overnight, and quick frozen in OCT. Because, in our previous reports, very little axonal regeneration had been noted on the nonconditioned side (the side without prior sciatic nerve injury) (7), counting and analysis (below) were reported here only on the conditioned side. Sections were cut at $10 \mu \mathrm{m}$ with a cryostat, floated on pretreated glass slides, and stored at $-80^{\circ} \mathrm{C}$. For analysis, sections were examined under a fluorescence microscope, and the number of fluorescently labeled cells was counted by 2 independent observers blinded to treatment. The same sections were then counterstained with cresyl violet to reveal the cell somas of all neurons in the DRG. Fluorescently labeled cells and total cells were counted in treated and control animals by an observer unaware of the treatment conditions. The percentage of labeled DRG cells in each animal was calculated. In order to determine labeled neuronal numbers accurately, the assumption-based method of Abercrombie was used, in which only cells with visible nucleoli are counted $(40,41)$. The expected total number of lumbar DRG neurons in mice is between 3,000 and 4,000 (42). A 1-way ANOVA with Bonferroni's correction for pairwise comparisons was used to test for differences between groups, with a significance level of $P<0.05$ adopted for all comparisons. Animals were treated with i.p. doses of FA, starting 3 days prior to the injury and given daily for 2 weeks.

ONRM. Surgery was performed on adult male Sprague-Dawley rats and male Folr $1^{+/+}$or $\mathrm{Folr}^{+/-}$mice. The optic nerve was exposed through a lateral orbital approach and cut within $1 \mathrm{~mm}$ of the globe. One end of an autologous sciatic nerve graft was attached to the optic stump, while the distal end was left to lie freely under the skin. Two months later, the incision was reopened under a similar anesthetic, and $5 \mu \mathrm{l}$ of the retrograde tracer Fluoro-Gold 


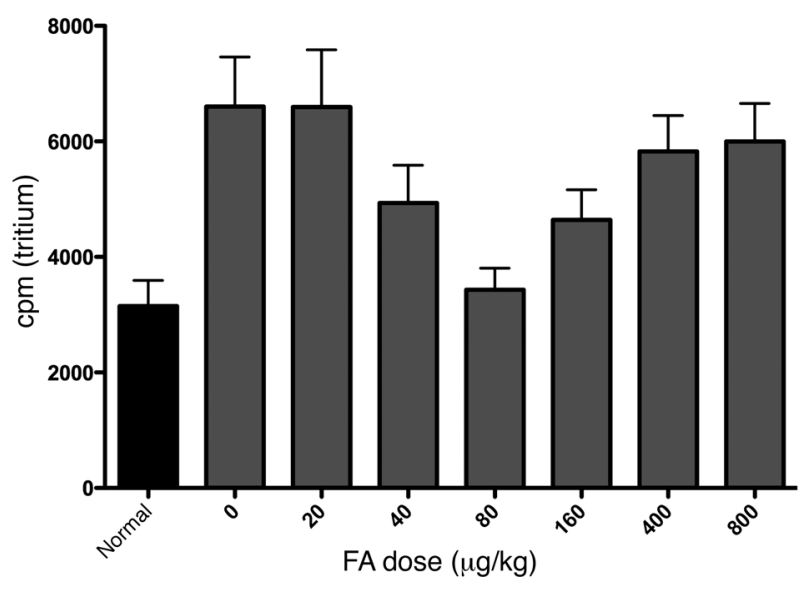

Figure 9

Global DNA methylation in the injured spinal cord follows a biphasic curve in response to increasing doses of FA. This curve corresponds to the biphasic Dnmt and Folr1 protein levels as well as the spinal regeneration response. We measured global methylation in the spinal cords of animals with combined spinal cord and peripheral nerve injuries, which were subjected to varying doses of i.p. FA given daily starting 3 days prior to the injury and continuing 4 days. $n=12$ (uninjured control animals); $n$ (FA dose) $=32(0 \mu \mathrm{g} / \mathrm{kg}) ; 33(20 \mu \mathrm{g} / \mathrm{kg})$;

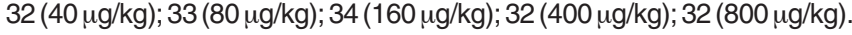
The quadratic term in the dose-response model was statistically significant $(P=0.001)$, confirming that there is a $U$-shaped dose response to the folate dose on a log scale. There are no differences between the injured/untreated animals and the animals treated with $20 \mu \mathrm{g} / \mathrm{kg}$ FA $(P=0.99)$, nor between the animals treated with the $400 \mu \mathrm{g} / \mathrm{kg}$ and $800 \mu \mathrm{g} / \mathrm{kg}$ doses $(P=0.85)$. Note the tight correlation in the biphasic FA dose effects between global DNA methylation, spinal regeneration (Figure 7F), and the Dnmt3a and Dnmt3b as well as Folr1 protein levels (Figure 7, A-C, and E). The FA dose of $80 \mu \mathrm{g} / \mathrm{kg}$, at which both DNA methylation and Dnmt3a and Dnmt3b and Folr1 expression levels were maximal, was found to be the most effective in promoting regeneration.

was placed into the graft at a distance of $1 \mathrm{~cm}$ from the globe. Twenty-four hours later, the animal was deeply anesthetized and perfused intracardially with $4 \%$ paraformaldehyde. The globe was removed and postfixed with $4 \%$ paraformaldehyde. The retina was dissected from the eyecup and examined under a fluorescence microscope. An observer unaware of the treatment conditions recorded the number of RGCs labeled with Fluoro-Gold. A 1-way ANOVA with Bonferroni's correction for pairwise comparisons was used to test for differences between groups with a significance level of $P<0.05$. The total number of RGCs in mice averages 50,000-60,000 (43), approximately $12 \%$ of which survive beyond a month after injury to the optic nerve (44).

\section{Folr molecular experiments in rats}

In situ bybridization. All steps preparing for and including in situ hybridization were completed in RNAse-free environments using sterile equipment, solutions, and technique. Preparation of the probe was accomplished following the oligonucleotide 3 ' end labeling protocol per manufacturer's instructions (Roche Applied Science). The oligonucleotide was combined with double-distilled water, $\times 5$ reaction buffer, $\mathrm{CoCl}_{2}$ solution, DIG-ddUTP solution, and terminal transferase, mixed, centrifuged briefly, and incubated at $37^{\circ} \mathrm{C}$ for 15 minutes. The reaction mixture was then placed on ice, and the reaction was stopped using 0.2 M EDTA. The labeling efficiency was determined by dot blot direct detection method according to the manufacturer's instructions (Roche Applied Science).
Slides containing up to 6 DRG sections were warmed and dried on a $50^{\circ} \mathrm{C}$ hot plate for 15 minutes. The slides were then fixed with $4 \% \mathrm{PFA}$ with diethyl pyrocarbonate-PBS (DEPC-PBS) for 20 minutes and washed with DEPC-PBS for 10 minutes. The slides were fixed with $4 \%$ PFA for another 10 minutes followed by an additional wash with DEPC-PBS for $10 \mathrm{~min}$ utes. A proteinase K solution was prepared in Genius buffer $(5 \mu \mathrm{l} / \mathrm{ml})$, and the slides were immersed for 10 minutes to remove endogenous proteins that may cause nonspecific hybridization. Five minute washes of PBS, $4 \%$ PFA fixative, and DEPC- $\mathrm{H}_{2} \mathrm{O}$ followed. The slides were then placed in an RNAse-free glass container with acetic anhydride in triethanolamine (TEA) buffer for 15 minutes with stirring for acetylation. Following a 5-minute PBS wash, the slides were dehydrated with successive methanol washes from $30 \%-100 \%$. The slides were then exposed to a prehybridization solution consisting of $\times 20$ SSC, $50 \%$ formamide, $10 \%$ SDS, $5 \%$ lauryl sarcosine, blocking reagent, and DEPC water. After 1 hour, the solution was replaced with the hybridization solution including the probe at the concentration determined by the dot blot direct detection assay, 1:25, and allowed to hybridize overnight at $42^{\circ} \mathrm{C}$ in a humid container.

The following day, the slides were immersed in successive washes of $1 \times$ SSC $-0.3 \%$ CHAPS and $1.5 \times$ SSC- $0.3 \%$ CHAPS at $60^{\circ} \mathrm{C}$ for 10 minutes each and then cooled to $37^{\circ} \mathrm{C}$. Next, the solution was replaced with $2 \times$ SSC $-0.3 \%$ $\mathrm{CHAPS}$ and $2 \times \mathrm{SSC}$ at $37^{\circ} \mathrm{C}$ for 20 minutes each. The slides were allowed to cool to room temperature, and $2 \times$ SSC- $0.3 \%$ CHAPS and $0.2 \times$ SSC $-0.3 \%$ CHAPS were administered at $60^{\circ} \mathrm{C}$ for 30 minutes each. PTW- $0.3 \%$ (where PTW consists of $0.1 \%[\mathrm{v} / \mathrm{v}]$ Tween 20 in PBS) CHAPS was then applied at $60^{\circ} \mathrm{C}$ for 2 minutes. At room temperature, PTW was applied for an additional 10 minutes followed by PBT (0.1 M PBS, pH 7.4, 0.1\% BSA, $0.2 \%$ Triton X-100) for 15 minutes. The slides were then incubated with $10 \%$ goat serum in PBT with $2 \mathrm{mM}$ levamisole for 1 hour at room temperature. The solution was then replaced with anti-digoxigenin-AP $(1: 1,000)$ in $2.5 \%$ goat serum, PBT, and levamisole and incubated overnight at $4{ }^{\circ} \mathrm{C}$.

On the final day, the slides were washed 3 times with PBT for 30 minutes each at room temperature. The slides were then washed with an alkaline phosphatase buffer for 5 minutes followed by the alkaline phosphatase buffer with levamisole for another 5 minutes. To stain with the hybridized probe, the slides were then incubated in alkaline phosphates buffer with nitro blue tetrazolium and 5-bromo-4-chloro-3-indolyl phosphate (NBT/ BCIP $90 \mu \mathrm{l} / \mathrm{ml}$ ), producing a color substrate to quantify hybridization efficiency. The slides were developed until color was evident and then immersed in deionized water. The slides were dried, mounted, and cover-slipped for preservation. Cells hybridized with the probe were counted using a fluorescence microscope by a reader blinded to the treatment status of the specimens. Specificity of the probe was controlled for by comparison of antisense-labeled slides with sense-labeled slides of corresponding DRGs. The number of stained neurons was counted by an observer unaware of the treatment conditions. Random sections in each of the control and experimental groups were then counterstained with cresyl violet to reveal the cell somas of all neurons in the DRG. The total cells were then counted in treated and control animals by an observer unaware of the treatment conditions. The percentage of labeled DRG cells in each animal was calculated.

Immunohistochemistry. On day 1 of the immunohistochemistry assay, the slides containing the DRG sections were rinsed 3 times with $0.1 \mathrm{M}$ PBS ( $\mathrm{pH}$ 7.4) for 5 minutes each time. The slides were then treated with $0.3 \%$ hydrogen peroxide in water for 10 minutes at room temperature to quench endogenous peroxidase, followed by another $0.1 \mathrm{M}$ PBS rinse. The slides were then incubated for 60 minutes at room temperature in blocking buffer $(5 \%$ goat serum and $0.3 \%$ Triton X-100 in PBS). Following incubation, the slides were transferred to a goat anti-Folr1 (ab2107) solution $(1: 20,000)$ and goat anti-Rfc1 (ab3566; Abcam) (1:2,000) in antibody-diluting buffer ( $2 \%$ goat serum and $0.2 \%$ Triton $\mathrm{X}-100$ in PBS) to incubate overnight at $4^{\circ} \mathrm{C}$. 

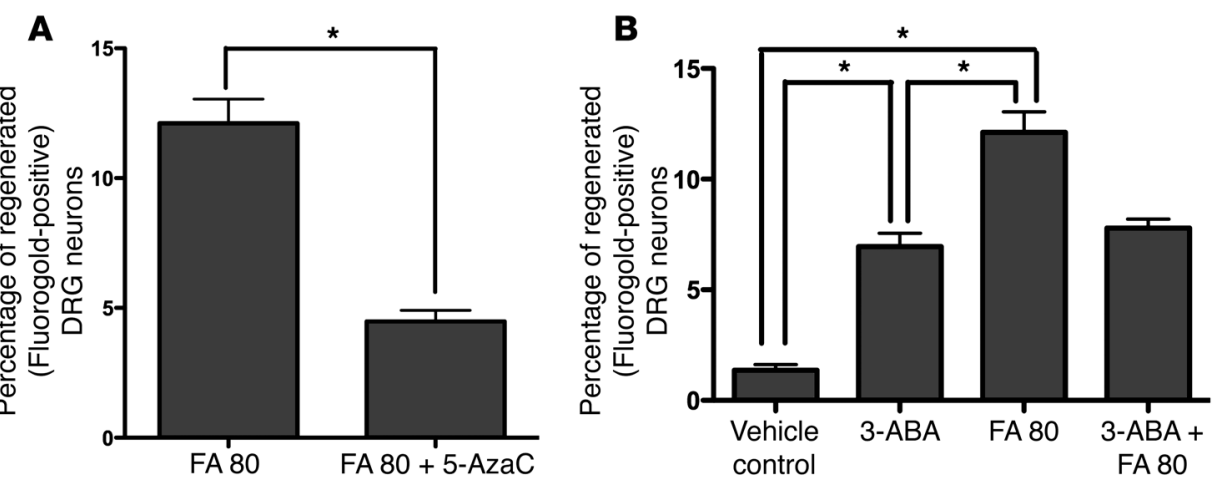

Figure 10

Dnmt agonist promotes, and Dnmt antagonist inhibits, the regeneration of injured sensory spinal axons into a peripheral nerve graft. Spinal axonal regeneration was measured in the SCRM model on the "conditioned" side after i.p. treatment with a Dnmt agonist 3-ABA (15 mg/kg) or antagonist $5-A z a C(0.1 \mathrm{mg} / \mathrm{kg})$ with and without FA at $80 \mu \mathrm{g} / \mathrm{kg}$. Treatment with the antagonist suppresses the proregenerative effect of FA (A). Conversely, treatment with the agonist at this dose significantly improves spinal regeneration into a nerve graft in vivo. The effect of $3-A B A$ at $15 \mathrm{mg} / \mathrm{kg}$ is equivalent to the $60 \mu \mathrm{g} / \mathrm{kg}$ dose of FA (7) (B). $n=7$ (FA); $n=9$ (FA and 5-AzaC); $n=11$ (vehicle control); $n=9$ (3-ABA); $n=7$ (FA); $n=9$ (FA and 3-ABA). One-way ANOVA with Bonferroni's correction; mean \pm SEM; ${ }^{*} P<0.05$.

The following day, the sections were rinsed with 0.1 M PBS 3 times for 10 minutes each time. This rinse was applied prior to and following each incubation step. The first incubation consisted of goat anti-mouse biotinylated secondary antibody (BA-2001; Vector Laboratories) (1:200) in antibody-diluting buffer for 1 hour at room temperature. An incubation with avidin-peroxidase followed (1:100 with antibody diluting buffer prepared 30 minutes prior, prepared using Vector Vectastain working solution protocol; Vector Laboratories) for 45 minutes at room temperature. After rinsing, the color reaction was developed with Vector DAB kit for 5-10 minutes. The slides were rinsed a final time with the $0.1 \mathrm{M}$ PBS 3 times for 10 minutes each time and allowed to air dry at room temperature overnight. On day 3 , the slides were dehydrated in alcohol and xylene, dried, and coverslipped using Permount (Fisher Scientific) solution. The number of stained neurons was counted by an observer blinded to treatment status. Random sections in each of the control and experimental groups were then counterstained with cresyl violet to reveal the cell somas of all neurons in the DRG. The total cells were then counted in treated and control animals by a blinded observer. The percentage of labeled DRG cells in each animal was calculated. Statistical significance was determined through Student's $t$ test analysis, with $P<0.05$ considered significant. Photomicrographs were made and digital images archived of all sections.

Immunohistochemistry for confocal microscopy. On day 1, the DRG slides were rinsed with $0.1 \mathrm{M} \mathrm{PBS}$ ( $\mathrm{pH} 7.4$ ) 3 times for 5 minutes each time and incubated in blocking buffer ( $5 \%$ horse serum and $0.3 \%$ Triton $\mathrm{X}-100$ in PBS) for 60 minutes at room temperature. Sections were then incubated in goat polyclonal $\alpha$-FR (M-19) 1 in 50 and mouse monoclonal neurofilament 1 in 500 in antibody-diluting buffer $(2 \%$ horse serum, $0.2 \%$ Triton $\mathrm{X}-100$ in PBS) overnight at $4^{\circ} \mathrm{C}$. On day 2 , the sections were rinsed with $0.1 \mathrm{M}$ PBS for 10 minutes, 3 times. Sections were then incubated with donkey anti-goat Alexa Fluor 596 (1:500) (red fluorescence for $\alpha$-FR [M-19]) and donkey anti-mouse Alexa Fluor 488 (1:1000) (green fluorescence for neurofilament) in antibody-diluting buffer for 1.5 hours at room temperature. The sections were then rinsed with $0.1 \mathrm{M}$ PBS ( $\mathrm{pH}$ 7.4) for 10 minutes, 3 times, then cover-slipped with Fluor Mount $\mathrm{G}$ for confocal microscopy.
Real-time PCR. $1 \mu \mathrm{g}$ of total RNA extracted from each spinal cord sample was used for cDNA production using oligo $(\mathrm{dt})_{15}$ and random hexamer primers with M-MuLV reverse transcriptase (Life Technologies). $10 \mathrm{ng}$ of cDNA and gene-specific primers were added to SYBR Green PCR Master Mix (Applied Biosystems) prior to PCR amplification ( 1 cycle at $50^{\circ} \mathrm{C}$ for 2 minutes, 1 cycle at $95^{\circ} \mathrm{C}$ for 10 minutes, and 40 cycles at $95^{\circ} \mathrm{C}$ for 15 seconds and $60^{\circ} \mathrm{C}$ for 1 minute) in a GeneAmp 5700 Sequence Detection System (Applied Biosystems). For each transcript, real-time PCR was conducted 3 times in duplicate using each of the RNA samples. The amplified transcript was quantified with the comparative $\mathrm{C}_{\mathrm{T}}$ method using 18S rRNA as the internal control (http://pebiodocs.com/ pebiodocs/04303859.pdf). The primer sequences were designed using Primer Express software (Applied Biosystems) based on the GenBank accession numbers (Rfc1: forward, GCACAGCTGAACTGGGATGA; reverse, CCAGAGGATGGCAGCGTAGA; Folr1: forward, CCTGCCATCCCTTCACTTTCT; reverse, CGCTCCCTCGGCTGTAGTT).

\section{Folr experiments in knockout mice}

Mice heterozygous for the folate-binding protein gene Folr1 (analogous to the human FOLR1) (courtesy Richard Finnell) were cross-bred. Folr $1^{-1}$ is an embryonic lethal, and the nullizygous pups do not survive to term (17). In the present investigation, the ONRM and SCRM surgery (as detailed above) were performed on Folr1 ${ }^{+/-}$heterozygous mice alongside WT Folr1 $1^{+/+}$ mice to assess spinal and optic axonal regeneration in vivo.

In vitro assays. Adult $\mathrm{Folr}^{+/+}$or $\mathrm{Folr}^{+/-}$mice were used for the in vitro assays. All animals underwent a spinal cord injury that consisted of sharply dividing the dorsal columns at C3 (as described above) as well as a left sciatic nerve transection to replicate the injuries created in the regeneration model (SCRM). Twenty-four hours after the injury, the animals were euthanized and the L4 and L5 ganglia were removed from the mice, dissociated, and centrifuged through a cushion of $10 \%$ Ficoll in F14 culture medium to remove myelinated axons, cellular debris, and nonneuronal cells as previously described (4). Neurons were resuspended in serum-free F14 medium containing N1 supplements and plated on poly-D-lysine/laminin-coated glass coverslips. Cells from 12-14 ganglia were plated in a 24-well plate for 18-24 hours, after which they were fixed in $4 \%$ paraformaldehyde for 30 minutes at room temperature (4). Quantitative analysis of neurite length and number of branch points per neurite was carried out on fixed cultures displayed on a video monitor using ImageJ software (http://rsbweb.nih. gov/ij/). Dilute cultures allowed unambiguous measurements of neurites. The longest processes from each cell were chosen for measurement, and all counts were made by an observer unaware of the treatment conditions. The percentage of DRG neurons that extended processes longer than $299 \mu \mathrm{m}$ was calculated after 24 hours.

\section{Dhfr and MS experiments in rats}

Animal surgery. Surgery was performed as detailed above (SCRM) to test regeneration in response to inhibitors of Dhfr (MTX; Parenta Pharmaceuticals) and MS (nitrous oxide; Material Distribution Service, University of 

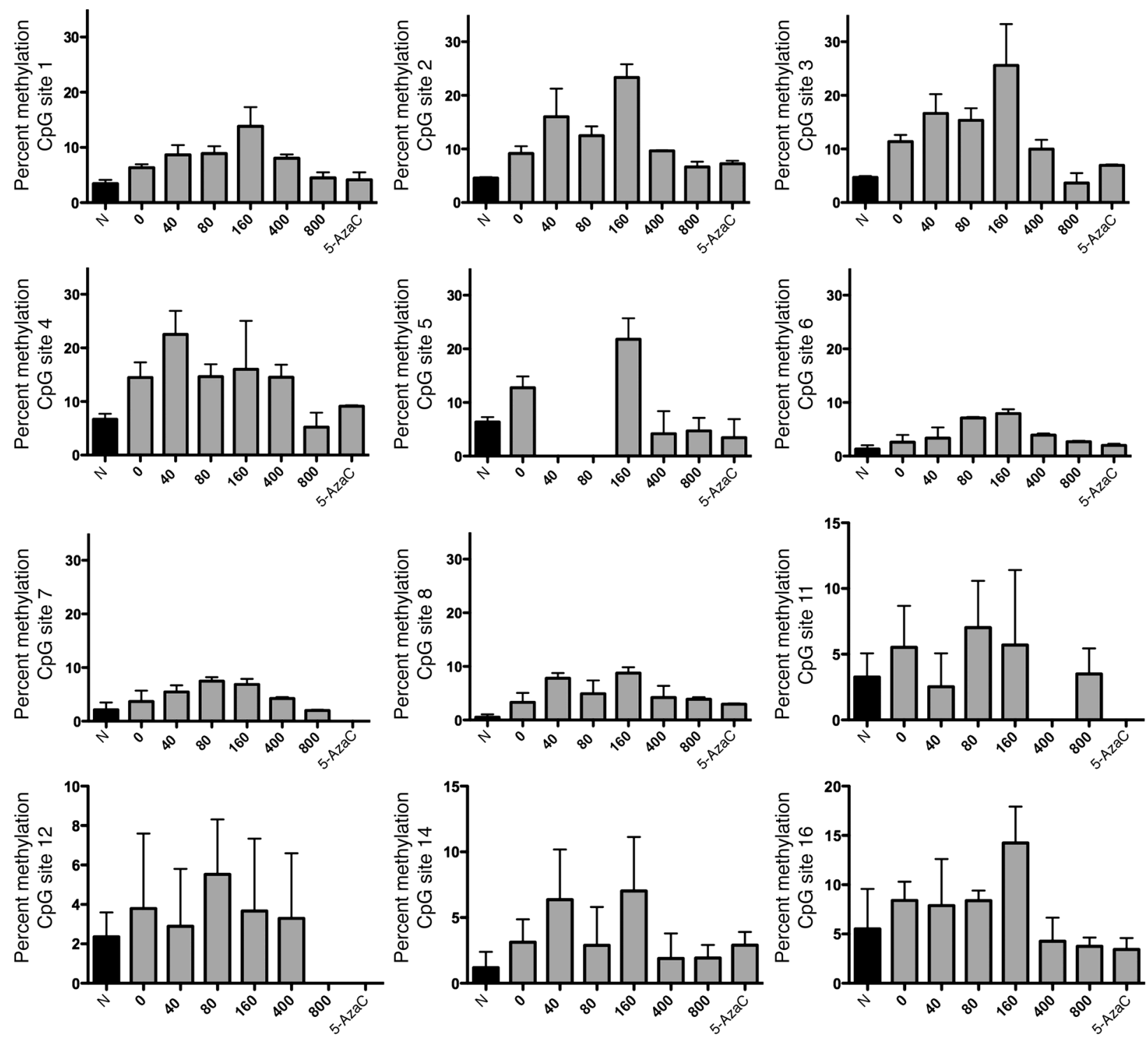

Figure 11

Combined spinal cord and peripheral nerve injury increases methylation of the Gadd45a promoter, and FA increases methylation further in a biphasic fashion in 12 of $18 \mathrm{CpG}$ sites. The spinal cords of animals subjected to combined spinal cord and left sciatic nerve injury (SCSN) and increasing i.p. concentrations of FA were removed for analysis. The percentage of methylation at each of $18 \mathrm{CpG}$ sites of the Gadd45a promoter was measured in triplicate using pyrosequencing. Note the biphasic response to FA in 12 of the sites studied. Most of the missing data on the graphs are caused by failed analysis by both software and manual analysis. For the samples with no data on any of the CpG sites, this is caused by failed PCR. Overall, the quadratic term in the dose-response models was statistically significant $(P=0.0001 ; n=3)$, confirming that there is a U-shaped dose-response to the folate dose. There is no evidence of differential dose responses among sites $(P=0.8)$, although power is low for identifying specific $\mathrm{CpG}$ sites with differing dose responses.

Wisconsin). The doses of MTX (400 $\mu \mathrm{g} / \mathrm{kg}$, i.p.) and nitrous oxide ( $80 \%$ $\mathrm{N}_{2} \mathrm{O}-20 \% \mathrm{O}_{2}$; 4-hour exposure 3 days prior to the injury, then 2-hour exposures every other day for 2 weeks) were selected from a literature review (45-48) and preliminary confirmatory experiments in our laboratory.

Dhfr assay. The Dhfr assay is based on the ability of Dhfr to catalyze the reversible NADPH-dependent reduction of dihydrofolic acid to tetrahydrofolic acid. Rats were treated with daily i.p. doses of MTX $(400 \mu \mathrm{g} / \mathrm{kg})$ for 3 days prior to spinal cord injury and for an additional 3 days after the injury. The injured spinal cords were then removed, homogenized, and subjected to the Dihydrofolate Reductase Assay Kit (CS0340; Sigma-Aldrich) according to the manufacturer's instructions.
MS assay. Frozen spinal cord samples were pulverized in liquid nitrogen using a porcelain mortar and pestle, and the powdered tissue was resuspended in a buffer containing $100 \mathrm{mM}$ potassium phosphate, pH 7.2, 0.24 M sucrose, aprotinin $(2 \mu \mathrm{g} / \mathrm{ml})$, PMSF $(25 \mu \mathrm{g} / \mathrm{ml})$, tosyl-Llysine chloromethyl ketone (TLCK) $(3 \mu \mathrm{g} / \mathrm{ml})$, and trypsin inhibitor $(3 \mu \mathrm{g} / \mathrm{ml})$. Homogenates were centrifuged, and MS activity was measured in cell-free extracts as described previously (22).

\section{DNA methylation experiments}

Treatments with FA, 3-ABA, or antagonist 5-AzaC. Sprague-Dawley rats were given i.p. injections of the following agents alone or in combination: 
Dnmt agonist, 3-ABA (15 mg/kg; Sigma-Aldrich); Dnmt antagonist, 5 -AzaC $(0.1 \mathrm{mg} / \mathrm{kg}$; Sigma-Aldrich); and FA at these concentrations: $0 \mu \mathrm{g} / \mathrm{kg}$ (untreated), $20 \mu \mathrm{g} / \mathrm{kg}, 40 \mu \mathrm{g} / \mathrm{kg}, 80 \mu \mathrm{g} / \mathrm{kg}, 160 \mu \mathrm{g} / \mathrm{kg}, 400 \mu \mathrm{g} / \mathrm{kg}$, and $800 \mu \mathrm{g} / \mathrm{kg}$. The daily i.p. injections, given under aseptic conditions, began 3 days prior to and continued until 4 days following the spinal cord injury. Throughout all protocols reported in this paper, $20 \mu \mathrm{l}$ of FA $5 \mathrm{mg} / \mathrm{ml}$ (APP Pharmaceuticals) was diluted in $\mathrm{DDH}_{2} \mathrm{O}$ as needed to obtain the final concentration.

Combined spinal cord and sciatic nerve injury surgery. The rats were subjected to a combined cervical spinal cord and sciatic nerve injury as detailed above (SCSN). Other rats were used as uninjured untreated controls. Four days following the injury, the animals were anesthetized, and the entire spinal cord was harvested for use in the experiments below.

DNA extraction and purification. Spinal cord tissue was lysed with proteinase $\mathrm{K}$ by vortexing. The tissue was then incubated at $55^{\circ} \mathrm{C}$ for $1-3$ hours. Buffer AL (QIAGEN) and 100\% ethanol were then aliquotted in succession with alternating vortexing and incubation periods until the solutions were completely homogenous. The mixtures were then transferred to DNeasy Mini Spin columns for washes with Buffer AW1 and Buffer AW2 (QIAGEN). With each wash, the mixture was centrifuged at $8,000 \mathrm{~g}$ and $20,000 \mathrm{~g}$, respectively, and flow-through was discarded. A final 2 aliquots of Buffer AE was then used to elute the purified total DNA from the final dry membrane.

Methylation incorporation assay. For methylation incorporation (23), $1 \mu \mathrm{g}$ of genomic DNA was combined with ${ }^{3} \mathrm{H}-\mathrm{SAM}$, SssI buffer, double-distilled water, and SssI enzyme. Control reactions lacking the enzyme were also prepared. After heating for 1 hour at $37^{\circ} \mathrm{C}$, the reaction mixture was aspirated through a Whatman DE-81 $2.3-\mathrm{cm}$ filter disk and successively washed with $50 \mathrm{mM}$ sodium phosphate buffer, 70\% ethanol, and $100 \%$ ethanol. The filter disk was then air dried and placed in a vial with scintillation fluid. The number of incorporated radioactively labeled methyl groups in the DNA sample was scored by a programmed scintillation counter. For statistical analysis, see below.

Biochemical determination of SAM and SAH spinal cord levels and SAM/SAH ratio. Spinal cord tissue was dissected and immediately homogenized with 5 volumes of perchloric acid $(0.4 \mathrm{M})$. Homogenates were centrifuged and the clear PCA extract stored at $-20^{\circ} \mathrm{C}$ until analysis. The SAM and SAH measurements were determined by HPLC coupled to UV detection as previously reported (49).

Methyltransferase Western blot analysis in mouse spinal cord. Protein $(30 \mu \mathrm{g})$ was separated by SDS-PAGE electrophoresis and transferred to the polyvinylidene difluoride membrane. The membranes were blocked with $5 \%$ milk in TBS containing $0.1 \%$ Tween- 20 followed by overnight incubation at $4^{\circ} \mathrm{C}$ with primary monoclonal antibodies diluted 1:500 (Dnmt1) and 1:250 (Dnmt3a and Dnmt3b) in washing buffer (0.05 M Tris-base, $0.5 \mathrm{M}$ $\mathrm{NaCI}, 0.05 \%$ Tween-20 in $\mathrm{H}_{2} \mathrm{O}$, pH 7.6). After several washes, secondary antibody goat anti-mouse IgG-HRP was added (1:4,000 in washing buffer) and incubated at room temperature for 1 hour. The membrane was washed and specific bands were observed using super signal detection reagents (Thermo Fisher Scientific). The total protein content was normalized using mouse anti-actin antibodies $(1: 5,000)$. Primary mouse monoclonal antibodies were as follows (Abcam): Dnmt1 (ab13573); Dnmt3a (ab13888); and Dnmt3b (ab13604). Secondary antibody goat anti-mouse antibody was as follows: IgG-HRP SC2005 (Santa Cruz Biotechnology Inc.). The densities of the bands were then measured using NIH ImageJ software relative to the densities of the corresponding actin bands. Data were plotted and statistical analyses performed using a 1-way ANOVA with Bonferroni's correction for pairwise comparisons, and statistical significance was defined as $P<0.05$ for all comparisons.

Spinal cord regeneration in response to Dnmt agonist or antagonist. In the rat SCRM above, the Dnmt agonist 3-ABA $(15 \mathrm{mg} / \mathrm{kg})$ or the antagonist 5 -AzaC $(0.1 \mathrm{mg} / \mathrm{kg})$ was given i.p. with or without $80 \mu \mathrm{g} / \mathrm{kg}$ of FA. All treat- ments were made with i.p. injections starting 3 days prior to surgery and given daily until 2 weeks after surgery.

Gadd45a methylation analysis. Pyrosequencing for allele quantification (PSQ H96A; QIAGEN Pyrosequencing) is a real-time sequencing-based DNA analysis that quantifies multiple and consecutive CPG sites individually (50). Rat Gadd45a methylation assay covers eighteen CG dinucleotides in the $5^{\prime}$ upstream region ranging from -211 to -12 in reference to the translational start site (start codon ATG' Ensembl: ENSRNOG00000005615). 500 ng of DNA samples was bisulfite modified using the EZ Methylation Kit (Zymo Research Inc.) PCR was performed using 10× PCR buffer, $3.0 \mathrm{mM}$ $\mathrm{MgCl}_{2}, 200 \mu \mathrm{M}$ of each dNTP, $0.2 \mu \mathrm{M}$ each of forward and reverse primers, 1.25 U HotStar DNA polymerase (QIAGEN), and approximately $10 \mathrm{ng}$ of bisulfite-converted DNA per $50 \mu \mathrm{l}$ reaction. PCR cycling conditions were as follows: $95^{\circ} \mathrm{C}, 15$ minutes; 45 cycles of $94^{\circ} \mathrm{C}, 30$ seconds; $56^{\circ} \mathrm{C}, 30$ seconds; $72^{\circ} \mathrm{C}, 30$ seconds; and $72^{\circ} \mathrm{C}, 5$ minutes. Products were then held at $4^{\circ} \mathrm{C}$.

PCR was performed with 1 of the PCR primers biotinylated to convert the PCR product to single-stranded DNA templates. PCR products (each $10 \mu \mathrm{l}$ ) were sequenced using the Pyrosequencing PSQ96 HS System (QIAGEN Pyrosequencing) following the manufacturer's instructions. Three separated sequencing reactions are needed to sequence the PCR amplicon. The methylation status of each locus was analyzed individually as an artificial T/C SNP using QCPG software (QIAGEN Pyrosequencing). Samples were run in triplicate for each of the experimental conditions. All pyrosequencing services were performed by EpigenDx Inc.

Statistics. All data are mean \pm SEM. Statistical significance was determined by Student's $t$ test or 1-way ANOVA with Bonferroni's correction for all pairwise comparisons, and a $P$ value less than 0.05 was considered significant. For the DNA methylation incorporation assay, a dose-response regression model was fit to the responses for injured animals that were treated with a folate dose of at least $20 \mu \mathrm{g} / \mathrm{kg}$, including linear and quadratic terms for log dose. The quadratic term is intended to capture a U-shape dose-response curve. All $P$ values are reported without correction for multiple comparisons. Note that decreased counts indicate increased methylation and vice versa. For pyrosequencing, a mixed-effects model with a random effect for animal was used to assess the overall relationship between folate dose and CPG site methylation. Linear and quadratic terms for log dose were again included in the model as fixed effects. For each site, percentage of methylation was first normalized by the overall site mean in order to account for site-to-site variations in response. Variation between sites in dose response was assessed using mixed-model-based ANOVA.

\section{Acknowledgments}

This work was supported by the Howard Hughes Medical Institute Pilot Project (to B.J. Iskandar), National Institute of Child Health and Human Development (NICHD) grant 1R01HD047516 (to B.J. Iskandar), NICHD grant 3R01HD047516-04S1 (to B.J. Iskandar), and NIH grants DK64959 (to R.V. Banerjee), DE016315 (to R.H. Finnell), and NS050249 (to R.H. Finnell). The authors would like to thank Dandan Sun, Raghu Vemuganti, Gordon Mitchell, Aron Troen, and Jean-Pierre Issa for reviewing drafts of the manuscript as well as Niki Virnig and Jill Schartner for technical assistance.

Received for publication May 27, 2009, and accepted in revised form February 24, 2010.

Address correspondence to: Bermans J. Iskandar, Department of Neurological Surgery, School of Medicine and Public Health, University of Wisconsin, 600 Highland Avenue, K4/832, Madison, Wisconsin 53792, USA. Phone: 608.263.9651; Fax: 608.263.1728; E-mail: iskandar@neurosurg.wisc.edu. 
1. Benowitz LI, Yin Y. Combinatorial treatments for promoting axon regeneration in the CNS: strategies for overcoming inhibitory signals and activating neurons' intrinsic growth state. Dev Neurobiol. 2007;67(9):1148-1165

2. Fawcett JW. The glial response to injury and its role in the inhibition of CNS repair. Adv Exp Med Biol. 2006;557:11-24

3. Yiu G,HeZ.Glial inhibition of CNS axon regeneration. Nat Rev Neurosci. 2006;7(8):617-627.

4. Bomze HM, Bulsara KR, Iskandar BJ, Caroni P, Skene JH. Spinal axon regeneration evoked by replacing two growth cone proteins in adult neurons. Nat Neurosci. 2001;4(1):38-43.

5. Rosenberg IH. Folic acid and neural-tube defects-time for action? NEnglJ Med. 1992;327(26):1875-1877.

6. [No authors listed.] Recommendations for the use of folic acid to reduce the number of cases of spina bifida and other neural tube defects. MMWR Recomm Rep. 1992;41(RR-14):1-7.

7. Iskandar BJ, et al. Folic acid supplementation enhances repair of the adult central nervous system. Ann Neurol. 2004;56(2):221-227.

8. Reynolds E. Vitamin B12, folic acid, and the nervous system. Lancet Neurol. 2006;5(11):949-960.

9. Finnell RH, et al. DNA methylation in Folbp1 knockout mice supplemented with folic acid during gestation. J Nutr. 2002;132(8 Suppl):2457S-2461S.

10. Helderman-van den Enden AT, et al. Monozygotic twin brothers with the fragile $\mathrm{X}$ syndrome: different CGG repeats and different mental capacities. JMed Genet. 1999;36(3):253-257.

11. Lau JC, Hanel ML, Wevrick R. Tissue-specific and imprinted epigenetic modifications of the human NDN gene. Nucleic Acids Res. 2004;32(11):3376-3382.

12. Mattson MP. Methylation and acetylation in nervous system development and neurodegenerative disorders. Ageing Res Rev. 2003;2(3):329-342.

13. Richardson PM, Issa VM. Peripheral injury enhances central regeneration of primary sensory neurones. Nature. 1984;309(5971):791-793.

14. Liu M, et al. Structure and regulation of the murine reduced folate carrier gene: identification of four noncoding exons and promoters and regulation by dietary folates. J Biol Chem. 2005;280(7):5588-5597.

15. Spiegelstein O, Eudy JD, Finnell RH. Identification of two putative novel folate receptor genes in humans and mouse. Gene. 2000;258(1-2):117-125.

16. Zhao R, Goldman ID. Resistance to antifolates. Oncogene. 2003;22(47):7431-7457.

17. Piedrahita JA, et al. Mice lacking the folic acid-binding protein Folbp 1 are defective in early embryonic development. Nat Genet. 1999;23(2):228-232

18. David S, Aguayo AJ. Axonal Elongation into peripheral nervous system "bridges" after central nervous system injury in adult rats. Science. 1981;214(4523):931-933.

19. Bolander-Gouaille C, Bottiglieri T. Homocysteine Related Vitamins and Neuropsychiatric Disorders. Paris, France: Springer-Verlag; 2003.

20. Yideng J, et al. Homocysteine-mediated expression of SAHH, DNMTs, MBD2, and DNA hypomethylation potential pathogenic mechanism in VSMCs. DNA Cell Biol. 2007;26(8):603-611.

21. Nunn JF. Clinical aspects of the interaction between nitrous oxide and vitamin B12. Br J Anaesth. 1987;59(1):3-13.

22. Banerjee R, Chen Z, Gulati S. Methionine synthase from pig liver. Methods Enzymol. 1997;281:189-196.

23. Balaghi M, Wagner C. DNA methylation in folate deficiency: use of CpG methylase. Biochem Biophys Res Commun. 1993;193(3):1184-1190.

24. Smith DS, Skene JH. A transcription-dependent switch controls competence of adult neurons for distinct modes of axon growth. $J$ Neurosci. 1997; 17(2):646-658.

25. Zardo G, Reale A, De Matteis G, Buontempo S, Caiafa P. A role for poly(ADP-ribosyl)ation in DNA methylation. Biochem Cell Biol. 2003; 81(3):197-208.

26. Lu S, Davies PJ. Regulation of the expression of the tissue transglutaminase gene by DNA methylation. Proc Natl Acad Sci U S A. 1997;94(9):4692-4697.

27. Di Giovanni S, Knoblach SM, Brandoli C, Aden SA, Hoffman EP, Faden AI. Gene profiling in spinal cord injury shows role of cell cycle in neuronal death. Ann Neurol. 2003;53(4):454-468.

28. Yamauchi J, et al. Gadd45a, the gene induced by the mood stabilizer valproic acid, regulates neurite outgrowth through JNK and the substrate paxillin in N1E-115 neuroblastoma cells. Exp Cell Res. 2007;313(9):1886-1896.

29. Ma DK, et al. Neuronal activity-induced Gadd45b promotes epigenetic DNA demethylation and adult neurogenesis. Science. 2009;323(5917):1074-1077.

30. Smith AD, Kim YI, Refsum H. Is folic acid good for everyone? Am J Clin Nutr. 2008;87(3):517-533.

31. Troen AM, et al. Unmetabolized folic acid in plasma is associated with reduced natural killer cell cytotoxicity among postmenopausal women. J Nutr. 2006;136(1):189-194.

32. Yideng J, Zhihong L, Jiantuan X, Jun C, Guizhong L, Shuren W. Homocysteine-mediated PPARalpha,gamma DNA methylation and its potential pathogenic mechanism in monocytes. DNA Cell Biol. 2008;27(3):143-150

33. Wollack JB, et al. Characterization of folate uptake by choroid plexus epithelial cells in a rat primary culture model. J Neurochem. 2008;104(6):1494-1503.

34. Zhao X, et al. Mice lacking methyl-CpG binding protein 1 have deficits in adult neurogenesis and hippocampal function. Proc Natl Acad Sci U S A. 2003;100(11):6777-6782.

35. Endres M, et al. DNA methyltransferase contributes to delayed ischemic brain injury. J Neurosci. 2000;20(9):3175-3181.

36. Robertson KD, Wolffe AP. DNA methylation in health and disease. Nat Rev Genet. 2000;1(1):11-19.

37. Miller CA, Sweatt JD. Covalent modification of DNA regulates memory formation. Neuron. 2007;53(6):857-869.
38. Isola LM, Gordon JW. Anemia in a line of transgenic mice carrying a mutant dihydrofolate reductase gene. Dev Genet. 1988;9(3):181-191.

39. Richardson PM, McGuinness UM, Aguayo AJ. Axons from CNS neurons regenerate into PNS grafts. Nature. 1980;284(5753):264-265.

40. Abercrombie M. Estimation of nuclear population from microtome sections. Anat Rec. 1946; 94:239-247.

41. Coggeshall RE, La Forte R, Klein CM. Calibration of methods for determining numbers of dorsal root ganglion cells. J Neurosci Methods. 1990;35(3):187-194.

42. Berg JS, Farel PB. Developmental regulation of sensory neuron number and limb innervation in the mouse. Brain Res Dev Brain Res. 2000;125(1-2):21-30.

43. Williams RW, Strom RC, Rice DS, Goldowitz D. Genetic and environmental control of variation in retinal ganglion cell number in mice. J Neurosci. 1996;16(22):7193-7205.

44. Robinson GA, Madison RD. Axotomized mouse retinal ganglion cells containing melanopsin show enhanced survival, but not enhanced axon regrowth into a peripheral nerve graft. Vision Res. 2004;44(23):2667-2674

45. Horne DW, Patterson D, Cook RJ. Effect of nitrous oxide inactivation of vitamin B12-dependent methionine synthetase on the subcellular distribution of folate coenzymes in rat liver. Arch Biochem Biophys. 1989;270(2):729-733.

46. Inoue K, Kudo G, Shimoda M, Kokue E. Potentiated decrease of plasma folate levels caused by the coadministration of folic acid in rats treated with methotrexate. J Vet Med Sci. 1998;60(4):503-507.

47. Koblin DD, Tomerson BW, Waldman FM. Disruption of folate and vitamin B12 metabolism in aged rats following exposure to nitrous oxide. Anesthesiology. 1990;73(3):506-512.

48. Royston BD, Nunn JF, Weinbren HK, Royston D, Cormack RS. Rate of inactivation of human and rodent hepatic methionine synthase by nitrous oxide. Anesthesiology. 1988;68(2):213-216.

49. Bottiglieri T. Isocratic high performance liquid chromatographic analysis of S-adenosylmethionine and S-adenosylhomocysteine in animal tissues: the effect of exposure to nitrous oxide. Biomed Chromatogr. 1990;4(6):239-241.

50. Brakensiek K, Wingen LU, Langer F, Kreipe H, Lehmann U. Quantitative high-resolution CpG island mapping with Pyrosequencing reveals disease-specific methylation patterns of the CDKN2B gene in myelodysplastic syndrome and myeloid leukemia. Clin Chem. 2007;53(1):17-23.

51. Alonso-Aperte E, Varela-Moreiras G. Brain folates and DNA methylation in rats fed a choline deficient diet or treated with low doses of methotrexate. Int J Vitam Nutr Res. 1996;66(3):232-236.

52. Schalinske KL, Steele RD. Methotrexate alters carbon flow through the hepatic folate-dependent one-carbon pool in rats. Carcinogenesis. 1996;17(8):1695-1700. 